\title{
energy fuels
}

\section{Process Engineering}

Modeling a Reaction Section of a Commercial Continuous Catalytic Reformer

Sa\&scaron;a Polovina, Merva Vojtech, Igor Dejanovic, Aleksandar Grujic, and Mirko Zoran Stijepovic

Energy Fuels, Just Accepted Manuscript • DOI: 10.1021/acs.energyfuels.7b03897 • Publication Date (Web): 10 Apr 2018

Downloaded from http://pubs.acs.org on April 11, 2018

\section{Just Accepted}

"Just Accepted" manuscripts have been peer-reviewed and accepted for publication. They are posted online prior to technical editing, formatting for publication and author proofing. The American Chemical Society provides "Just Accepted" as a service to the research community to expedite the dissemination of scientific material as soon as possible after acceptance. "Just Accepted" manuscripts appear in full in PDF format accompanied by an HTML abstract. "Just Accepted" manuscripts have been fully peer reviewed, but should not be considered the official version of record. They are citable by the Digital Object Identifier (DOI®). "Just Accepted" is an optional service offered to authors. Therefore, the "Just Accepted" Web site may not include all articles that will be published in the journal. After a manuscript is technically edited and formatted, it will be removed from the "Just Accepted" Web site and published as an ASAP article. Note that technical editing may introduce minor changes to the manuscript text and/or graphics which could affect content, and all legal disclaimers and ethical guidelines that apply to the journal pertain. ACS cannot be held responsible for errors or consequences arising from the use of information contained in these "Just Accepted" manuscripts. 


\title{
Modeling a Reaction Section of a Commercial Continuous Catalytic Reformer
}

Saša Polovina ${ }^{a}$, Merva Vojtech $^{b}$, Igor Dejanović $^{c}$, Aleksandar Grujić ${ }^{d}$, Mirko Stijepovicel

${ }^{\mathrm{a} I N A / S T S I ~-~ M O L, ~ L o v i n c ̌ i c ́ e v a ~ 4, ~} 10000$ Zagreb, Croatia

${ }^{\mathrm{b}}$ INA-MOL d.d., Avenija V. Holjevca 10, P.P.555, 10020 Zagreb, Croatia

${ }^{\mathrm{c}}$ Faculty of Chemical Engineering and Technology, University of Zagreb, Marulićev trg 19, 10000 Zagreb, Croatia

${ }^{\mathrm{d}}$ Institute of Chemistry, Technology and Metallurgy, University of Belgrade, Njegoševa 12, 11000 Belgrade, Serbia

${ }^{\mathrm{e}}$ Faculty of Technology and Metallurgy, University of Belgrade, Karnegijeva 4, 11000 Belgrade, Serbia

\begin{abstract}
Continuous Catalytic reforming (CCR) is known to convert refinery naphtha into a high-octane liquid product, also known as the reformate. In this paper, a First Principle Reaction Section Model for a CCR process is presented. Even though CCR is a well-established technology, the application of advanced, real-time optimization techniques that are able to quickly respond to any imposed changes onto the process, are necessary in the refinery business. This becomes particularly important as a result of profit margin changes, operating cost changes, and the introduction of new environmental legislations. Hence, we present a kinetic model for the CCR process using the so called "lumped" concept. The reactors have been modeled using a quasisteady-state approach. The unknown model parameters have been estimated by bench marking the First Principle Reaction Section results with a commercial CCR process owned by the
\end{abstract}

\footnotetext{
${ }^{1}$ Address. Faculty of Technology and Metallurgy, University of Belgrade, Karnegijeva 4, 11000 Belgrade, Serbia

email: mstijepovic@tmf.bg.ac.rs 
Hungarian Oil and Gas Public Limited Company (INA-MOL). The proposed model has been tested, and compared to data obtained from an existing CCR plant. The predictions of the model were found to be in good agreement with the experimental data. The relative absolute errors between the measured and model estimated variables have been found to be lower than $2 \%$. The relative absolute error associated with the required fired heater duties were less than $1.0 \%$. To simulate the reaction section of the CCR process requires less than 0.1 seconds of CPU time, which clearly indicates that this model can be very suitable for carrying out optimization studies. Moreover, this study shows that although there is fluctuation in composition of feedstock, lumped kinetic approach was capable to well predict behavior of CCR process.

Keywords: Modeling, Parameter Estimation, Commercial, Naphtha Catalytic Reformer

\section{Introduction}

Catalytic Naphtha Reforming (CNR) is one of the most fundamental processes in the oil refinery business ${ }^{1}$. For many years, its primary role has been to upgrade low octane gasoline to a high octane number ${ }^{2}$. Today CNR processes are also being used as a valuable hydrogen source. Hydrogen is known to be one of the cleanest low-carbon fuels. Lately, there has been an increased demand for cleaner fuel sources, as a result of many new environmental legislations. Not only is hydrogen considered a clean fuel, in fact, it can also be used as a key reactant for the production of many other clean fuels. Hydrogen is also known for its ability to enhance the conversion of crude oil.

Cleaner fuels are often produced in Hydrogen Treating Units, by removing hetero atoms (such as sulfur, nitrogen, oxygen) through hydrogenolysis. This is often followed by saturating the olefinic and aromatic bonds ${ }^{3}$. Hydrogen is also the key component in Hydrogen Processing 
Units, where low molecular weight products are produced by breaking the C-C bonds of hydrocarbon molecules that are found in heavy crude oil residue ${ }^{4}$. It is worth mentioning that both Hydrogen Treating Units and Hydrogen Processing Units require a hydrogen purity of at least $95 \%$ by Volume ${ }^{4}$. Therefore, if a CNR process is to be used as a hydrogen source, it is essential that high purity hydrogen is achievable via CNR, to avoid any extra treatment and purification related expenses.

The CNR process is the most prominent source of hydrogen from an oil refinery. CNR processes often produce large hydrogen quantities, with purities that could reach as high as $95 \%$ by Volume ${ }^{5}$. External Hydrogen Generation Units are often required to satisfy refinery hydrogen demands that could not be covered internally by the CNR process. Hydrogen production via Steam Methane Reforming, or Partial Oxidation are often used by Hydrogen Generation Units ${ }^{6}$. Steam Methane Reforming techniques are highly effective, and can generate hydrogen rich streams with purities that can reach up to $95 \%$ by Volume ${ }^{6}$. Even though Partial Oxidation is known to be a more costly process, the main advantage of Partial Oxidation over Steam Methane Reforming is its ability to convert low quality by-products, such as fuel gas, into hydrogen rich streams ${ }^{6}$. However, it should be noted that Hydrogen Generation Units are costly, being three times more expensive than $\mathrm{CNR}^{6}$. Moreover, Hydrogen Generation Units that utilize Steam Methane Reforming techniques for hydrogen production consume 3 moles of methane for each mol of hydrogen produced ${ }^{6}$, leading to very high carbon footprints. Therefore, increasing "internal" hydrogen production from the CNR unit within the refinery can drastically reduce the impact of hydrogen production on the refinery's operating cost, as well as its overall carbon footprint

\section{Background}


The catalytic reforming technology has undergone tremendous advances over the past couple of decades. The main guidelines for improved CCR performance can be summarized by the following two main aspects: (1) operate at a pressure that is as-low-as-possible, and (2) maximize the duration of the process cycle.

There are three major technologies used in CNR processes: Semi-Regenerative Catalytic Reforming (SRCR), Cyclic Regenerative Catalytic Reforming (CRCR), and Continuous Catalytic Reforming (CCR). The first CNR units were designed using the SRCR technology ${ }^{5}$. For a long time, SRCR was the only type of catalytic reforming technology available ${ }^{5}$. An SRCR process mainly consists of a sequence of adiabatic reactors with a fixed catalyst bed. The endothermic nature of the SRCR process causes a decreases in reaction mixture temperature, which can be compensated by re-passing the mixture through a series of fired heaters. However, it should be noted that the SRCR technology has the following limitations: (i) need for periodical shut-down to allow for catalyst regeneration, (ii) need for high operating pressure (20-35 bar) to decrease coking and deactivation rates, (iii) higher loss of liquid product due to cracking reactions, (iv) lower production rate and purity of produced hydrogen, (v) reduction of reformate yield during catalytic cycle, and (vi) product quality is not constant ${ }^{7}$. Due to the many limitations associated with the SRCR process, this technology has been replaced with the CRCR and CCR alternatives ${ }^{5}$.

CRCR operates on the same principles as SRCR. It consists of a set of radial fixed bed adiabatic reactors, where one of the reactors is always on standby, and ready to replace any of the operating reactors after the catalyst reaches the end of its catalytic activity ${ }^{7}$. CRCR operates well under a broad range of process pressures (3.5-17.0 barg), which enables the production of high quality products, with Research Octane Numbers (RONs), that can reach up to $108^{7}$. Hydrogen 
obtained from CRCR processes can reach up to $93 \%$ by Volume ${ }^{7}$. However, CRCR hydrogen product quality is not always constant, since the catalyst activity decreases with operating time, and catalyst cannot be regenerated back to optimal conditions.

Unlike the SRCR and CRCR techniques, the CCR process was later introduced, and involves the catalyst being continuously regenerated in separate units before being transferred back to the reforming process ${ }^{2}$. CCR systems can operate well under low pressure conditions, without the risk of catalyst deactivation. At 3.5 bars, CCR processes can yield high quality products with RONs as high as $108^{2}$. Moreover, reformate yield losses in CCR are lower when compared to SRCR. A relatively low operating CCR pressures can increase the rate of hydrogen production, due to a reduction in the rate of cracking reactions ${ }^{7}$. Additionally, CCR often results in higher quality hydrogen, in comparison to SRCR ${ }^{7}$. On the other hand, investment costs and utility consumption in CCR processes are higher than SRCR ${ }^{2,7}$. Nevertheless, the relatively high reformate and hydrogen yields from a CCR process can offset its high operating costs, resulting high returns on investment ${ }^{7}$. Therefore, more than $95 \%$ of new catalytic reformers are designed using the CCR technology $y^{5}$. Moreover, many existing SRCR units have been re-vamped into CCR units ${ }^{5}$.

There are two main international providers of CCR technologies: UOP (also known as the Platforming process) and Axens ${ }^{1}$. Both licensors operate using the same design principles, with slight differences in equipment arrangement. For instance, the UOP design consists of a set of adiabatic reactors positioned upright, allowing free gravitational flow of the catalyst from the top of the first reactor to the bottom of last reactor ${ }^{8}$. The exhausted catalyst from the bottom of last reactor is then sent to a regenerator via hydrogen lifts. Regenerated catalyst is then returned back to the top of the first reactor ${ }^{8}$. The Axens design employs a set of radial adiabatic reactors 
arranged in sequence, which is a very similar setup to the SRCR process ${ }^{9}$. Gas lifts are used to transport the catalyst (1) between the different reactors, and (2) between the reactor section and regenerator section ${ }^{9}$.

Further ways to improve CNR processes are still being researched. In fact, four major CCR research areas have been identified:

- Area 1: continuous hydrogen removal from the reaction mixture using membrane reactors ${ }^{10}$; using this reactor type would not only increase the reaction rate, but also lower the overall energy consumption, and enable safer operations ${ }^{10}$.

- Area 2: decreasing the pressure drop of a CNR process: because pressure drop significantly affects the yield and the operating conditions of the process ${ }^{11-14}$; employing reactors with lower pressure drop, such as radial-flow spherical reactor and axial-flow spherical reactor is often recommended ${ }^{14}$.

- Area 3: decreasing the energy requirements of a CNR process; fired heaters require substantial amounts of fuel to run the CNR process. A solution to this problem would be to couple the endothermic CNR process with exothermic processes ${ }^{15,16}$. Moreover, energy requirements can further be reduced using plate heat exchangers for feed preheating, instead of the classical shell and tube heat exchangers ${ }^{17}$. This results in increased heat recovery and significant pressure drop reductions.

- Area 4: running the CNR process under isothermal conditions; this leads to an increased product yield and an improved quality of hydrogen produced, since many desirable reactions are stimulated. To maintain isothermal conditions, Stijepović et al. ${ }^{18}$ proposed new reactor types that can employ super conducting media or heating via microwaves. 
Although, the CCR process is a well-established technology, the development of advanced realtime optimization models for CCR systems can enable the process to quickly respond to unpredictable challenges ${ }^{19}$. A First Principle Model that employs real-time optimization techniques has many advantages over Linear Programming models, and statistical regression methods. This is because First Principle Models are able to predict the CCR process yield and the operating costs associated with the process more accurately, which is critical for identifying the optimal CCR operating strategy ${ }^{1}$. There are several CCR models depicted in literature ${ }^{20-23}$. Even though Lee et al. employ a relatively simple kinetics scheme proposed by Bommannan et al ${ }^{24}$, their work does not consider adjustable parameters that would allow benchmarking with commercial CCR units ${ }^{23}$. Hou et al. modeled CCR process using commercial process simulator. This model also does not enable adjusting model with commercial data ${ }^{21}$. On the other hand, Iranshahi et al. extended the kinetic model proposed by Padmavathi and Chaudhuri ${ }^{25}$, and presented a rigorous $\mathrm{CCR}$ model based on a system of partial differential equations ${ }^{22}$. Although their model has been validated using industrial data, no calibration procedure has been provided. Chang et al. utilized a commercial software, which is developed for the UOP CCR process ${ }^{20}$. This paper presents the development of a First Principle Reaction Section Model for CCR process. A comprehensive model has been obtained by conducting an extensive literature survey. Industrial data that describe the CCR process operating conditions, as well as inlet and outlet process stream flowrates and compositions have been considered. Model unknown parameters are estimated by bench marking the model results against data from commercial CCR plant. The proposed approach results in parameters with tight confidence intervals, indicating robustness and improved CCR model accuracy for a wide range of operating conditions. 


\section{Process Description}

Figure 1 illustrates a commercial plant flowsheet of the entire CCR process. The feedstock (S-1) is first mixed with recycle gas (S-17). The resulting stream (S-2) is heated in heat exchanger (E101) and directed to a fired heater (H-101) where the mixed feedstock is heated to the required reaction temperature $(\mathrm{S}-4)$.

\section{Figure 1 CCR Process Flowsheet}

Stream S-4 enters into a set of reactors (R-101 to R-104) and fired heaters (H-102 to H-104) where the reactants are converted into products. The reactor effluent from the last reactor (S-11) is cooled using preheating feed, in heat exchanger (E-101). The reactor effluent is further cooled using an air cooler (A-101), and then sent into a low-pressure separator (F-101) to separate hydrogen vapor (S-14) from remaining liquid (S-28). Following this separation step, the hydrogen-rich gas stream (S-14) enters a recirculation compressor (K-101), and is then split into two process streams that are rich in hydrogen (S-16 and S-17). Stream S-17 is recycled and mixed with hydrocarbon feedstock while stream S-16 is cooled down using an air cooler (A102). After cooling, stream S-18 is mixed with an overhead gas stream (S-49) from distillation column (C-101), and is then directed to a water cooling unit (W-101). Following the water cooler, stream S-20 is compressed to the required pressure of the refinery hydrogen network using a set of drums (F-102/3) and booster compressors (K-102/3). The compressed stream (S27) is mixed with stream S-29. The resulting mixture is further cooled using a water cooler unit (W-103). The resulting two phase gas-liquid mixture is then re-separated using a high pressure separator (F-104). Re-mixing at high pressure not only increases the hydrogen content in the hydrogen-rich gas stream (due to the condensation of heavy hydrocarbons), but also increases the 
amount of hydrogen produced as a result of extracting $\mathrm{H}_{2}$ from the unstablized reformate stream, in addition to increasing the amount of liquid product due to hydrocarbon condensation from the hydrogen-rich gas. The overhead hydrogen-rich stream (S-32) from the flash vessel F-104 undergoes further purification using a pressure swing system (D-101 A/B) before being sent to the hydrogen distribution lines.

The unstabilized reformate stream (S-41), from the bottom of the separator (F-104), is preheated in using heat exchanger (E-102), and is then sent to a debutanizer column (C-101). The distillate from the top of the column (A-105 and W-104) is then condensed and collected in an overhead receiver (F-105). The liquid phase (S-45) from the overhead receiver (F-105) is the final commercial product, which goes to the refinery liquid petrol gas (LPG) pool. Since the gas stream (S-46) from top of the overhead receiver (F-105) consists of light hydrocarbons and residual hydrogen, it is considered the main component of the refinery fuel system. The liquid stream from the bottom of the stabilization column is the main reformate product (S-57). Lastly, the reformate can be cooled down and sent to a blending tank, or to a distillation column train.

According to the process description provided above, the CCR process consists of three main stages: (1) a reaction stage, (2) a regeneration stage and (3) a separation stage. The reaction stage can be identified as the core of the CCR process. Hence, an appropriate kinetic model for the CNR process must consider all the components and reactions that are involved in the process.

There have been two different and notable kinetic modeling techniques for CNR systems: the "lumped approach" and the "single event approach" 26,27. The "lumped approach" applies a grouping technique using a number of molecules in a single pseudo-component or "lump", based on a pre-specified set of criteria ${ }^{26}$. This approach is most commonly used in CNR kinetic 
modeling ${ }^{26}$. Kinetic models that adopt the lumped approach are often characterized as simple, easy-to-estimate models that do not require much data. Therefore, such kinetic models can easily be incorporated into integrated flowsheets, since they require little CPU time to solve, which makes them very suitable for optimization studies ${ }^{20}$. Once major drawback of the lumped approach is that the kinetic parameters are very sensitive to changes in feed composition. Therefore, different kinetic parameters have to be re-estimated for different feedstocks ${ }^{27}$. Quann and Jaffe ${ }^{28}$, as well as Wei et al. ${ }^{29,30}$ have been able to address this problem by upgrading the concept of the lumps. Both methods are able to generate synthetic feedstcks which can satisfy the observed chemical and physical characteristics. However, both Sotelo-Boyas and Froment, have stated that the major drawbacks of lumped modeling have still not been resolved using the aforementioned approaches ${ }^{27}$.

The second CNR kinetic modeling approach, or the "single event approach", is known to involve thousands of reactions and hundreds of species. According to this approach, an algorithm generates a reaction network based on a number of fundamental reactions. The major advantage of using the "single-event "concept is that rate parameters are truly invariant with respect to the feedstock composition, and the prediction of the reformate composition is much more accurate and reliable, even for a wide range of operating conditions ${ }^{27}$. However, the complexity of this approach is a major drawback, since it requires the development of an algorithm that could generate the reaction network. In addition, a commercial software is often required to estimate several parameters in kinetic model. Moreover, several experimental measurements are required for estimating single-event kinetic parameters ${ }^{27}$. Currently, no commercial data is available with respect to how much CPU time it takes to perform single-event kinetic calculations. In addition, 
no kinetic parameters are available to benchmark the model performance against a commercial CNR unit.

The guidelines for the development of an FPR for a CNR process are outlined by Turpin ${ }^{31}$, which mainly consist of: (i) an objective definition, (ii) model selection, (iii) data collection, (iv) validation, and (v) verification. To develop a First Principle Model for the CNR reaction stage, Turpin's guidelines have been slightly modified. The respective modifications are described in following sections. Moreover, a description of the experimental procedure, as well as the data processing step is provided in the following sections. The applied kinetic model and process chemistry have also been outlined, as well as the modeling of a moving bed reactor system. Most importantly, the parameter estimation strategy for the kinetic model has been presented.

\section{Experimental and data consistency}

Mathematical models that are based on first principles are usually characterized by a number of unknown parameters, which in turn have to be estimated using a set of the experimental data. Since the proposed model has a set of unknown parameters, data has been collected from a CCR plant owned by INA-MOL ${ }^{32}$, in order to estimate those unknown parameters. Sets of operating parameters data such as: temperature, pressure, flowrates of fuel and air consumed in fired heaters; have been collected from the refinery SCADA system. Composition data have been collected by taking samples from streams S-1, S-17, S-37, S-48, S-50 and S-57 presented in Figure 1. It is worth mentioning that most of the data was collected during a testing period in which a fresh catalyst was introduced. The catalyst performance has been tested for a wide range of operating conditions, as shown in Table 1. 


\section{Table 1. Range of operating conditions}

Samples taken from stream S-1 (the feedstock) and S-57 (the reformate) have been analyzed using a Gas Chromatography machine using ASTM D5134 (PONA) method ${ }^{33}$. Moreover, a more detailed composition analysis of several samples of feedstock using the ASTM D6839 method was also obtained ${ }^{34}$. The main reason for employing an additional ASTM D6839 method for obtaining a more detailed composition analysis, was to avoid using any feed characterization methods that are associated with $3-10 \%$ error ${ }^{1}$. Moreover, consistency between the two different methods have been checked. Gas streams (S-17, S-37 and S-50) were analyzed using the UOP 539 method $^{35}$, while the LPG stream (S-48) was analyzed using the EN 27941 method ${ }^{36}$. The coke content of the catalyst before and after regeneration was also determined using ASTM D5373 method ${ }^{37}$.

The feedstock is a mixture of straight run naphtha and gasoline produced in vacuum gas oil hydrocrackings units and vacuum residue hydrocracking units. Even though the same fractions of straight run naphtha and gasoline produced in hydrocracking units are mixed, the feedstock compositions were found to deviate from sample to sample. In Table 2, the minimum and maximum values of weight fractions of feedstock and reformate are given (for each component). The compositions of recycle gas, net hydrogen, fuel gas and LPG were also found to fluctuate, as shown in Table 3. The coke weight fraction on the catalyst before and after regeneration are provided in Table 4. 
Table 2. Composition ranges of feedstock and reformate in $\mathrm{wt} \%$

Table 3. Composition ranges of recycle gas, net hydrogen, LPG and fuel gas in mol \% Table 4. Composition ranges of coke before and after regeneration

Experimental data consistency has been verified using two different criteria proposed by Turpin

31. The first criterion for verifying data consistency uses the absolute relative error of material balances between the feedstock stream (S-1) and the product streams (S-37, S-48, S-50 and S-57) at the process battery limit. The absolute relative error associated with the material balance of a given data set is defined according to Eq. (1) below:

$\boldsymbol{E r r}, \%=\frac{\left|\boldsymbol{m}_{\text {feedstock }}-\boldsymbol{m}_{\text {reforamte }}-\boldsymbol{m}_{L P G}-\boldsymbol{m}_{F G}-\boldsymbol{m}_{\text {net_H }}\right|}{\boldsymbol{m}_{\text {feedstock }}} \cdot 100$

If the absolute relative error given by Eq. (1) of a data set is less than $1 \%$, the set is then identified suitable for parameter estimation. The absolute relative error was found to be less than $1 \%$ for $78 \%$ of our collected data. Hence, most of the data sets were found suitable for parameter estimation.

Data sets that pass the first criterion are then tested using the second criterion. The second criterion is based on the absolute relative error of a hydrogen material balance, which can estimated between the inlet and outlet streams at the process battery limit. The absolute relative error associated with the hydrogen material balance for a given data set is defined according to Eq. (2) below.

$\operatorname{Err}_{H}, \%=\frac{\left|\boldsymbol{w}_{H}^{\text {feedstock }} \cdot \boldsymbol{m}_{\text {feedstock }}-w_{H}^{\text {reformate }} \cdot \boldsymbol{m}_{\text {reforamte }}-w_{H}^{L P G} \cdot \boldsymbol{m}_{L P G}-w_{H}^{F G} \cdot \boldsymbol{m}_{F G}-w_{H}^{\text {net } H} \cdot \boldsymbol{m}_{\text {net_H }}\right|}{\boldsymbol{w}_{H}^{\text {feedstock }} \cdot \boldsymbol{m}_{\text {feedstock }}} \cdot 100$ 
According to Turpin, if the absolute relative error given by Eq. (2) is less than $0.5 \%$, the data set can be identified suitable for parameter estimation ${ }^{31}$. Less than $5 \%$ of our collected data were found to have an absolute relative error of less than $0.5 \%$, using the hydrogen material balance criterion. Other work such as Chang et al. faced the same problem, and discovered that the main cause of this may be attributed to inaccuracies associated with flowrate measurement ${ }^{20}$. Therefore, the upper limit to accept a data set based on the hydrogen material balance absolute relative error was increased to $2.5 \%$, and $85 \%$ of the collected data passed this criterion.

\section{Process chemistry and reaction model}

There have been plenty of studies which have been conducted to understand the chemistry of bifunctional catalysts used in CNR processes ${ }^{20,26,38-40}$. It was revealed that the chemical mechanism of the process consists of four major reaction types: isomerization, dehydrogenation, cyclization and cracking. Since isomerization, cyclization and cracking reactions are exothermic in nature, they can be catalyzed via the acid functional group of a bifunctional catalyst. On the other hand, dehydrogenation reactions are endothermic in nature and can be catalyzed via the metal functional group of a bifunctional catalyst since ${ }^{39}$. It has been noted that paraffinic components need to undergo all four types of reactions, while naphthenic components do not undergo cyclization ${ }^{38}$. Moreover, since naphthenic components can rapidly be converted into aromatics, cracking reactions rarely occur ${ }^{38}$. In case of an aromatic feedstock, hydrodealkylation reactions are present ${ }^{38}$.

In order to establish a mathematical formulation of the CNR process, two different kinetic modeling techniques can be developed. Chang et al. ${ }^{20}$ and Ancheyeta ${ }^{26}$ compares the development process of the different kinetic modeling techniques, and discusses the notable key difference. 
In this study, the kinetic models reported by Marin et al, and van Trimpont have been used as reference models ${ }^{39,40}$. Both kinetic model belong to the group of "lumped" models, and incorporate Hougen-Watson kinetics, in which the rate equations explicitly account for the interactions between the chemical species and the catalyst ${ }^{39}$. Because it is a "lumped" model, the lumps, or pseudo-components, need to be defined. For this, the components of a typical reaction mixture have been distributed to a proper lump based on the type of components, as well as the number of carbon atoms present in the different component types. Eight different lumps, or pseudo-component types, were defined based on the component types: normal paraffins, paraffins with a single branch, paraffins with multiple branches, alkylcyclopentanes, alkylcyclohexanes, aromatics, olefins and light gases. Each pseudo-component type has also been divided according to the number of carbon atoms based on the following: (1) normal, single branch and multi branch paraffins contain hyrocarbons fractions from 6 to 11 carbon atoms., (2) alkylcyclopentanes contain hydrocarbons fractions from 5 to 11 carbon atoms, (3) alkylcyclohexanes, aromatics, olefins contain hyrocarbons fractions from 6 to 11 carbon atoms and (4) light gasses contain hydrocarbon fractions between 1 to 5 carbon atoms. Based on the procedure described above, 51 different chemical species have been defined (16 pure components and 35 pseudo-components). Table 5 summarizes the complete list of defined chemical species.

\section{Table 5. List of pure components and pseudo-components}

Thermodynamic properties of each of the listed pseudo-components were estimated using the summation of the corresponding pure component fractions that constitute the pseudo-component, multiplied by the specified property. Pure components fractions have been estimated by 
evaluating equilibrium compositions of pure components that constitute the pseudo-component at the referenced Weighted Average Inlet Temperature, and the average operating pressure. The equilibrium compositions were estimated according to the procedure proposed by White et al ${ }^{41}$.

Having defined the different chemical species, and using the models reported by Marin et al and van Trimpont et al., a kinetics model has been established ${ }^{39,40}$. The kinetics scheme presented in Table 6 accounts for seven different reaction types: (i) isomerization of normal and single branch paraffins, (ii) n-paraffin cyclization, (iii) naphthene isomeriztion, (iv) dehydrogenation of nparaffins, (v) dehydrogenation of naphthenes to aromatics, (vi) cracking of paraffins, and (vii) coke formation.

The isomerization of parrafins can occur between normal and single branch paraffins, as well as between single branch and multi branch parrafins. This reaction is often characterized by a high reaction rate. It is often assumed that normal parrafins are the only chemical species that are able to undergo a cyclization reaction to produce alkylcyclopentane. This observation is consistent with the findings reported by van Trimpont ${ }^{40}$. The isomerization of naphthene reactions can occur between alkylcyclopentanes and alkylcyclohexanes. The isomerization of naphthenes is characterized by a high reaction rate, just like the isomerization of paraffins. The alkylcyclohexanes undergo dehydrogenation reactions, which are very fast and endothermic. It is worth mentioning that the kinetics scheme reported by Marin et al. ${ }^{39}$ and van Trimpont ${ }^{40}$ does not account for the dehydrogenation of paraffins. This is because the experimental conditions which have been applied in both cases involved a relatively high hydrogen partial pressure (20 bar), which suppresses the paraffin dehydrogenation reaction to a great extent. The commercial CCR process was found to operate at much lower hydrogen partial pressure conditions (3.5 bar), compared to Marin et al. and van Trimpont ${ }^{39,40}$; hence, a small amount of olefins was reported 
to be present in the reformate (Table 2). Therefore, it was found very important to include olefinic components in this work, in order to be able to track the olefin quantities, and establish an appropriate material balance. The proposed kinetic scheme accounts for the dehydrogenation of paraffins as an additional reaction. As far as cracking reactions which have been considered, the same concept which has been proposed by Marin et al. has been applied ${ }^{39}$. In doing so, the paraffins have been assumed to undergo a series of cracking reactions that result in a wide product distribution ranging from light gases all the way to paraffins with at least 6 or more carbon atoms ${ }^{39}$.

Coke formation in the kinetic scheme was based on the study by Van Trimpont et al. ${ }^{40}$. For this, they defined three major reactions that greatly contributed to coke formation. Two of the contributing reactions were alkylcyclopentadienes with aromatics, and alkylcyclohexadienes with aromatics. The third contributing reaction originates from dienes. The compositions of dienes, alkylcyclopentadienes, and alkylcyclohexadienes were hard to track, because of their low concentrations in the system. Therefore, their surface concentrations were assumed to be proportional to the partial pressure of n-paraffins, alkylcyclopentanes, and alkylcyclohexanes. Hence, the coke formation reactions have been expressed using the partial pressure of nparaffins, alkylcyclopentanes, and alkylcyclohexanes. In summary, Table 6 lists all the reactions which have been employed in the CNR kinetic model.

\section{Table 6. Proposed kinetics model and kinetic parameters}

After the kinetics scheme has been established, the reaction rates for isomerisation, cyclization, dehydrogenation, and cracking were all defined according to following general form: 


$$
\boldsymbol{r x n}_{r x, r, i_{r}, j_{r}}^{o}=\zeta_{r x} \frac{\boldsymbol{k}_{F r x, r, i_{r}, j_{r}}\left(\prod_{c \in C}\left(\operatorname{vreak}_{c, r x} \cdot \boldsymbol{P}_{c, r, i_{r}, j_{r}}^{\text {vreak }_{c, r x}}\right)-\boldsymbol{k}_{B r x, r, i_{r}, j_{r}} \cdot \prod_{c \in C}\left(\operatorname{vprod}_{c, r x} \cdot \boldsymbol{P}_{c, r, i_{r}, j_{r}}^{v p r o d_{r}}\right)\right)}{\left(\boldsymbol{P}_{H r, i_{r}, j_{r}} \cdot \gamma_{r, i_{r}, j_{r}}\right)^{\beta_{r x}}\left(\boldsymbol{P}_{H r, i_{r}, j_{r}} \cdot \theta_{r, i_{r}, j_{r}}\right)^{2 \cdot\left(1-\beta_{r x}\right)}}
$$

Where the forward reaction rate constant can be defined as:

$$
\boldsymbol{k}_{F r x, r, i_{r}, j_{r}}=\exp \left(\operatorname{Aref}_{r x}-\frac{\text { Eref }_{r x}}{\boldsymbol{R}_{g a s} \boldsymbol{T}_{r, i_{r}, j_{r}}}\right)
$$

Where the backward reaction rate constant can be defined as:

$$
\boldsymbol{k}_{\boldsymbol{B} r \boldsymbol{r}, \boldsymbol{r}, \boldsymbol{i}_{r}, \boldsymbol{j}_{r}}=\boldsymbol{K r e f}_{r x} \exp \left(-\frac{\Delta \boldsymbol{H r x n _ { r x } ^ { o }}}{\boldsymbol{R}_{\text {gas }}}\left(\frac{1}{\boldsymbol{T}_{r e f}}-\frac{1}{\boldsymbol{T}_{r, i_{r}, j_{r}}}\right)\right)
$$

The adsorption term for the acid function can be defined as:

$$
\begin{aligned}
\gamma_{r, i_{r}, j_{r}} & =\frac{\boldsymbol{P}_{H, r, i_{r}, j_{r}}+\boldsymbol{K}_{G} \sum_{c g \in C G} \boldsymbol{P}_{c g, r, i_{r}, j_{r}}+\boldsymbol{K}_{\boldsymbol{P}}\left(\sum_{c n \in C N} \boldsymbol{P}_{c n, r, i_{r}, j_{r}}+\sum_{c s \in C S} \boldsymbol{P}_{c s, r, i_{r}, j_{r}}+\sum_{c m \in C M} \boldsymbol{P}_{c m, r, i_{r}, j_{r}}\right)}{\boldsymbol{P}_{H, r, i_{r}, j_{r}}} \\
+ & \frac{\boldsymbol{K}_{N}\left(\sum_{c p \in C P} \boldsymbol{P}_{c p, r, i_{r}, j_{r}}+\sum_{c h \in C H} \boldsymbol{P}_{c h, r, i_{r}, j_{r}}\right)+\boldsymbol{K}_{A} \sum_{c a \in C A} \boldsymbol{P}_{c a, r, i_{r}, j_{r}}}{\boldsymbol{P}_{H, r, i_{r}, j_{r}}}
\end{aligned}
$$

The adsorption term for the metal function can be defined as:

$$
\theta_{r, i_{r}, j_{r}}=1+\boldsymbol{K}_{6 N} \sum_{c h \in C H} \boldsymbol{P}_{c h, r, i_{r}, j_{r}}+\boldsymbol{A}_{m t} \exp \left(-\frac{\boldsymbol{H}_{m t}}{\boldsymbol{R}_{g a s} \boldsymbol{T}_{r, i_{r}, j_{r}}}\right) \frac{\sum_{c h \in C H} \boldsymbol{P}_{c h, r, i_{r}, j_{r}}}{\boldsymbol{P}_{H, r, i_{r}, j_{r}}^{2}}
$$

Based on the Van Trimpont ${ }^{40}$ model, we proposed a novel expression for the coke formation rate which includes all components, as follows: 


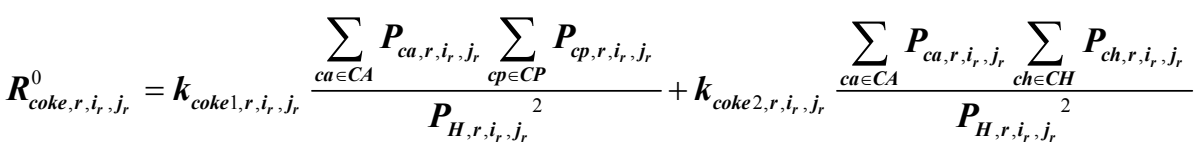

$$
\begin{aligned}
& +\boldsymbol{k}_{c o k e 3, r, i_{r}, j_{r}} \frac{\sum_{c n \in C N} \boldsymbol{P}_{c n, r, i_{r}, j_{r}}}{\boldsymbol{P}_{H, r, i_{r}, j_{r}}}
\end{aligned}
$$

Where the reaction rate constants can be defined as:

$$
\begin{aligned}
& \boldsymbol{k}_{\text {cokel }, \boldsymbol{r}_{i}, \boldsymbol{i}_{r}, j_{r}}=\boldsymbol{A}_{\text {cokel }} \exp \left(-\frac{\boldsymbol{E} \boldsymbol{a}_{\text {cokel } 1}}{\boldsymbol{R}_{g a s} \boldsymbol{T}_{r, i_{r}, j_{r}}}\right) \\
& \boldsymbol{k}_{\text {coke } 2, \boldsymbol{r}_{i}, j_{r}, j_{r}}=\boldsymbol{A}_{\text {coke } 2} \exp \left(-\frac{\boldsymbol{E} \boldsymbol{a}_{\text {coke } 2}}{\boldsymbol{R}_{g a s} \boldsymbol{T}_{r, i_{r}, j_{r}}}\right) \\
& \boldsymbol{k}_{\text {coke } 3, \boldsymbol{r}_{i}, j_{r}, j_{r}}=\boldsymbol{A}_{\text {coke } 3} \exp \left(-\frac{\boldsymbol{E} \boldsymbol{a}_{\text {coke } 3}}{\boldsymbol{R}_{g a s} \boldsymbol{T}_{r, i_{r}, j_{r}}}\right)
\end{aligned}
$$

The heat of reaction for isomerization, cyclization, dehydrogenation, and cracking can be expressed using the following general form:

$$
\Delta \operatorname{Hrxn}_{r x, r, i_{r}, j_{r}}=-\sum_{c \in C}\left(\operatorname{vreak}_{c, r x} \operatorname{Hcomp}_{c, r, i_{r}, j_{r}}\right)+\sum_{c \in C}\left(\operatorname{vprod}_{c, r x} \operatorname{Hcomp} p_{c, r, i_{r}, j_{r}}\right)
$$

Similarly, the heat of reaction for the coke formation reaction can be expressed as follows:

$$
\Delta H r x n_{c o k e, r, i_{r}, j_{r}}=-\sum_{c \in \in C C}\left(\operatorname{vcoke}_{c c} \operatorname{Hcomp} p_{c c, r, i_{r}, j_{r}}\right)+\operatorname{Hcomp} p_{c o k e, r, i_{r}, j_{r}}
$$

The rate of reaction for all chemical species (except coke) can be defined using the following general equation:

$$
\begin{aligned}
& r_{c, r, i_{r}, j_{r}}=\sum_{r x \in R x}\left[\left(\operatorname{vprod}_{c, r x}-\operatorname{vreak}_{c, r x}\right) \cdot r x n_{r x, r, i_{r}, j_{r}}^{o} \cdot \phi_{r x, r, i_{r}, j_{r}}\right] \\
& \phi_{r x,, r, i_{r}, j_{r}}=\phi_{A, r, i_{r}, j_{r}}^{\beta_{r x}} \cdot \phi_{M,, r, i_{r}, j_{r}}^{\left(1-\beta_{r x}\right)} \\
& =\exp \left(-\alpha_{A} \cdot \operatorname{Cok}_{\boldsymbol{r}, \boldsymbol{i}_{r}, j_{r}} \cdot \beta_{r x}\right) \cdot \exp \left[-\alpha_{\boldsymbol{M}} \cdot \boldsymbol{C o k}_{\boldsymbol{r}, \boldsymbol{i}_{r}, j_{r}} \cdot\left(1-\beta_{r x}\right)\right]
\end{aligned}
$$

The rate of reaction for coke formation with catalyst deactivation, can be expressed as follows: 


$$
\boldsymbol{R}_{c o k e, r, i_{r}, j_{r}}=\boldsymbol{R}_{c o k e, r, i_{r}, j_{r}}^{0} \cdot \phi_{c o k e, r, i_{r}, j_{r}}=\boldsymbol{R}_{c o k e, r, i_{r}, j_{r}}^{0} \cdot \exp \left(-\alpha_{C} \cdot \text { Coke }_{r, i_{r}, j_{r}}\right)
$$

\section{CNR Reactor Model}

Figure 2 illustrates a simple moving bed radial flow reactor scheme. Since the reaction stage of a CCR process mainly consists of a set of moving bed radial flow reactors coupled with fired heaters, the reactor section model must be able to capture both the reactor performance, the fired heater performance, as well as any the links between them. In this section, the overall reaction section model is explained.

\section{Figure 2. a) Moving bed radial flow reactor, b) Layers of moving bed, c) Reaction zones}

A radial flow reactor is often used because a low pressure drop is preferred. The catalyst slowly moves downward between two perforated co-axial cylinders. The reaction mixture enters from the very top of each reactor, and crosses the catalyst bed. The coke deposits are progressively formed on the catalyst surface as it moves downwards throughout the reactor. The coke distribution is not uniform, because the concentration of reactants has been noted to be diverse along the reactor. Additionally, the mixing of catalyst pellets within reactor is negligible. To rigorously model the reactor, a system of partial differential equation must be established ${ }^{22,42}$. A numerical solution could be very time consuming, so this approach would be impractical to use in optimization studies, especially when a recycle stream is involved. This is why a quasi-steadystate approach which has been proposed by Stijepović et al has been employed in this work ${ }^{42}$.

To do so, each moving bed reactor (Figure 2a) is split in so-called reaction zones by dividing it into a set of layers in radial and axial direction, as illustrated by Figure $2 \mathrm{~b}$. The gas phase reaction mixture enters and moves through reaction zone in radial direction (Figure $2 \mathrm{c}$ ). It is assumed that change of gas phase reaction mixture can be modelled as adiabatic plug flow 
reactor. Catalyst pellets enter the reaction zone from top and move to its bottom in axial direction (Figure 2c). The coke formation rate is much slower comparing to other reactions in the process, which is why it is assumed that coke concentration within the reaction zone is uniform. Therefore, it is assumed that the change of coke concentration on catalyst surface can be modelled as continuous stirred tank reactor using radial direction inlet gas compositions in reaction zone for calculating rate of coke formation. Based on aforementioned, it can be stated that a two dimensional model is established.

The reaction zone material balance can be defined as:

$$
\frac{d F_{c, r, i_{r}, j_{r}}}{d W_{r, i_{r}, j_{r}}}=r_{c, r, i_{r}, j_{r}} \quad \forall c \in C, \forall r \in R c, \forall i_{r} \in I_{r}, \forall j_{r} \in J_{r}
$$

The reaction zone energy balance can be defined as:

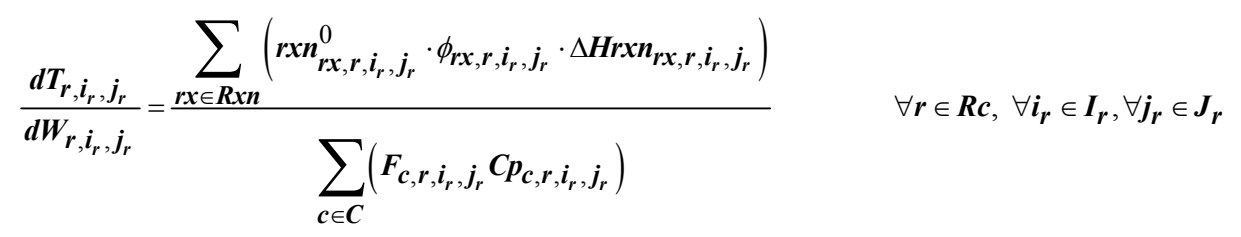

The reaction zone pressure change can be defined as:

$$
\frac{d \text { Press }_{r, i_{r}, j_{r}}}{d W_{r, i_{r}, j_{r}}}=\Delta p_{\text {const }} \quad \forall r \in R c, \forall i_{r} \in I_{r}, \forall j_{r} \in J_{r}
$$

The reaction zone coke formation balance can be defined as:

$$
\frac{\text { Coke }_{r, i_{r}, j_{r}+1}-\text { Coke }_{r, i_{r}, j_{r}}}{W_{r, i_{r}, j_{r}}}=\frac{1}{U_{t}} R_{c o k e, r, i_{r}, j_{r}} \quad \forall r \in R c, \forall i \in I_{r}, \forall j \in J_{r}
$$

The inlet component molar flowrate in every $1^{\text {st }}$ reaction zone of each reactor $r$ can be defined as:

$$
F_{c, r, i_{r}, 1}^{i n}=\frac{i n F_{c, r}}{z N_{r}} \quad \forall c \in C, \forall r \in R c, \forall i_{r} \in I_{r}
$$


The initial condition for flowrate of component $c$ of each reaction zone can be defined as:

$$
\boldsymbol{F}_{\boldsymbol{c}, \boldsymbol{r}, i_{r}, j_{r}}^{\text {in }}=\boldsymbol{F}_{\boldsymbol{c}, \boldsymbol{r}, \boldsymbol{i}_{\boldsymbol{r}}, j_{\boldsymbol{r}}}(0) \quad \forall \boldsymbol{c} \in \boldsymbol{C}, \forall \boldsymbol{r} \in \boldsymbol{R} \boldsymbol{c}, \forall \boldsymbol{i}_{\boldsymbol{r}} \in \boldsymbol{I}_{\boldsymbol{r}}, \forall \boldsymbol{j}_{\boldsymbol{r}} \in \boldsymbol{J}_{\boldsymbol{r}}
$$

The outlet component molar flowrate from each reaction zone can be defined as:

$$
F_{c, r, i_{r}, j_{r}}^{\text {out }}=F_{c, r, i_{r}, j_{r}}\left(W_{r, i_{r}, j_{r}}^{\text {total }}\right) \quad \forall c \in C, \forall r \in R c, \forall i_{r} \in I_{r}, \forall j_{r} \in J_{r}
$$

The inlet component molar flowrate to next reaction zone can be defined as:

$$
\boldsymbol{F}_{c, r, i_{r}, j_{r}}^{\text {in }}=\boldsymbol{F}_{c, r, i_{r}-1, j_{r}}^{\text {out }} \quad \forall c \in C, \forall \boldsymbol{r} \in \boldsymbol{R} c, \forall i_{r} \in \boldsymbol{I}_{r}, \forall j_{r} \in J_{r}
$$

The outlet component molar flowrate for each reactor can be defined as:

$$
\sum_{i \in I_{r}} F_{c, r, i_{r}, r N_{r}}^{\text {out }}=\text { out } F_{c, r} \quad \forall c \in C, \forall r \in R c
$$

The inlet component flowrate to next reactor $r$ can be defined as:

$$
\text { in } F_{c, r+1}=o u t F_{c, r} \quad \forall c \in C, \forall r \in R c
$$

The inlet temperature in each $1^{\text {st }}$ reaction-zone of each reactor can be defined as:

$$
T_{r, i_{r}, 1}^{i n}=i n T_{r} \quad \forall r \in R c, \forall j_{r} \in J_{r}
$$

The initial condition for temperature of each reaction zone can be defined as:

$$
\boldsymbol{T}_{r, i_{r}, j_{r}}^{i n}=\boldsymbol{T}_{r, i_{r}, j_{r}}(0) \quad \forall r \in R c, \forall i_{r} \in \boldsymbol{I}_{r}, \forall \boldsymbol{j}_{r} \in \boldsymbol{J}_{r}
$$

The outlet temperature from each reaction-zone can be defined as:

$$
\boldsymbol{T}_{r, i_{r}, j_{r}}^{\text {out }}=\boldsymbol{T}_{r, i_{r}, j_{r}}\left(\boldsymbol{W}_{r, i_{r}, j_{r}}^{\text {total }}\right) \quad \forall \boldsymbol{r} \in \boldsymbol{R} c, \forall i_{r} \in \boldsymbol{I}_{r}, \forall \boldsymbol{j}_{r} \in \boldsymbol{J}_{r}
$$

The inlet temperature to next reaction zone can be defined as:

$$
\boldsymbol{T}_{r, i_{r}, j_{r}}^{\text {in }}=\boldsymbol{T}_{\boldsymbol{r}, \boldsymbol{i}_{r}-1, j_{r}}^{\text {out }} \quad \forall \boldsymbol{r} \in \boldsymbol{R} \boldsymbol{c}, \forall \boldsymbol{i}_{\boldsymbol{r}} \in \boldsymbol{I}_{\boldsymbol{r}}, \forall \boldsymbol{j}_{\boldsymbol{r}} \in \boldsymbol{J}_{\boldsymbol{r}}
$$

The outlet temperature from each reactor can be defined as:

$$
\frac{\sum_{i_{r} \in I_{r}} \boldsymbol{T}_{r, i_{r}, r N_{r}}^{\text {out }}}{z N_{r}}=\text { out } \boldsymbol{T}_{r} \quad \forall \boldsymbol{r} \in \boldsymbol{R} \boldsymbol{c}
$$

The inlet pressure in each $1^{\text {st }}$ reaction-zone of each reactor can be defined as: 


$$
\text { Press }_{r, 1, j_{r}}^{i n}=\text { inPress }_{r} \quad \forall \boldsymbol{r} \in \boldsymbol{R} c, \forall j_{r} \in J_{r}
$$

The initial condition for pressure of each reaction zone can be defined as:

$$
\operatorname{Press}_{r, i_{r}, j_{r}}^{\text {in }}=\operatorname{Press}_{r, i_{r}, j_{r}}(0) \quad \forall \boldsymbol{r} \in \boldsymbol{R} c, \forall \boldsymbol{i}_{r} \in \boldsymbol{I}_{\boldsymbol{r}}, \forall \boldsymbol{j}_{\boldsymbol{r}} \in \boldsymbol{J}_{\boldsymbol{r}}
$$

The outlet pressure from each reaction-zone can be defined as:

$$
\operatorname{Press}_{r, i_{r}, j_{r}}^{\text {out }}=\text { Press }_{r, i_{r}, j_{r}}\left(\boldsymbol{W}_{r, i_{r}, j_{r}}^{\text {total }}\right) \quad \forall \boldsymbol{r} \in \boldsymbol{R} c, \forall \boldsymbol{i}_{r} \in \boldsymbol{I}_{\boldsymbol{r}}, \forall \boldsymbol{j}_{r} \in \boldsymbol{J}_{\boldsymbol{r}}
$$

The inlet pressure to next reaction zone can be defined as:

$$
\operatorname{Press}_{r, i_{r}, j_{r}}^{\text {in }}=\text { Press }_{r, i_{r}-1, j_{r}}^{\text {out }} \quad \forall r \in R c, \forall i_{r} \in I_{r}, \forall j_{r} \in J_{r}
$$

The outlet pressure for each reactor can be defined as:

$$
\frac{\sum_{i_{r} \in I_{r}} \text { Press }_{r, i_{r}, r N_{r}}^{\text {out }}}{z N_{r}}=\text { outPress }_{r} \quad \forall r \in R c
$$

The inlet pressure in the next reactor can be defined as:

$$
\text { inPress }_{r+1}=\text { outPress }_{r} \quad \forall r \in R c
$$

The inlet coke in each $1^{\text {st }}$ reaction-zone in the axial direction for each reactor can be defined as:

$$
\text { Coke }_{r, 1, j_{r}}^{\text {in }}=\frac{\text { inCoke }_{r}}{r N_{r}} \quad \forall r \in R c, \forall j_{r} \in J_{r}
$$

The initial condition for coke concentration of each reaction zone can be defined as:

$$
\operatorname{Cok}_{\boldsymbol{r}, i_{r}, j_{r}}^{i n}=\text { Coke }_{r, i_{r}, j_{r}}(0) \quad \forall r \in R c, \forall i_{r} \in I_{r}, \forall j_{r} \in J_{r}
$$

The outlet coke concentration from each reaction-zone can be defined as:

$$
\operatorname{Coke}_{r, i_{r}, j_{r}}^{\text {out }}=\text { Coke }_{r, i_{r}, j_{r}}\left(W_{r, i_{r}, j_{r}}^{\text {total }}\right) \quad \forall r \in R c, \forall i_{r} \in I_{r}, \forall j_{r} \in J_{r}
$$

The inlet coke concentration to next reaction zone can be defined as:

$$
\operatorname{Coke}_{r, i_{r}, j_{r}}^{\text {in }}=\text { CokeT }_{r, i_{r}, j_{r}-1}^{\text {out }} \quad \forall r \in R c, \forall i_{r} \in I_{r}, \forall j_{r} \in J_{r}
$$

The outlet coke content for each reactor can be defined as: 


$$
\sum_{j \in J_{r}} \text { Coke }_{r, z N r, j_{r}}^{o u t}=\text { outCoke }_{r} \quad \forall r \in R c
$$

The inlet coke flowrate into the next reactor can be defined as:

inCoke $_{r+1}=$ outCoke $_{r} \quad \forall r \in R c$

The heat required to increase temperature of reaction mixture from the outlet temperature of reactor $r$ to an appropriate reaction temperature for the of next reactor $r+1$ is expressed as:

$$
H_{f h}=\sum_{c \in C} \text { out } F_{c, r} \int_{\text {out } T_{r}}^{\text {in } T_{r+1}} C_{p_{c, r}} \cdot d T_{f h} \quad \forall c \in C, \forall f h \in F H, \forall r=f h
$$

\section{Parameter Estimation}

In each reaction zone, the model is composed of individual sets of differential and algebraic equations that describe the change in the reaction mixture. These individual sets of differential and algebraic equations use several linking points (i.e material and energy balances) between the different CNR reaction zones. Hence, the overall reaction model is a very large, highly nonlinear system of Differential Algebraic Equations, which can be defined according to the following:

$$
\begin{aligned}
& \Omega_{i, j}\left[\frac{d F_{c, r, i_{r}, j_{r}}}{d W_{r, i_{r}, j_{r}}}, \frac{d T_{r, i_{r}, j_{r}}}{d W r, i_{r}, j_{r}}, \frac{d P r e s s_{r, i_{r}, j_{r}}}{d W_{r, i_{r}, j_{r}}}, \frac{d \text { Coke }_{r, i_{r}, j_{r}}}{d W r, i_{r}, j_{r}}, F_{c, r, i_{r}, j_{r}}, T_{r, i_{r}, j_{r}}, \text { Press }_{r, i_{r}, j_{r}}, \text { Coke }_{r, i_{r}, j_{r}}, W_{r, i_{r}, j_{r}}, \Psi\right]=0
\end{aligned}
$$

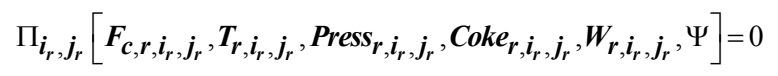

$$
\begin{aligned}
& \boldsymbol{F}_{\boldsymbol{c}, \boldsymbol{r}, \boldsymbol{i}_{\boldsymbol{r}}, j_{\boldsymbol{r}}}(0)=\delta\left[\boldsymbol{F}_{\boldsymbol{c}, \boldsymbol{r}, \boldsymbol{i}_{\boldsymbol{r}}-1, \boldsymbol{j}_{\boldsymbol{r}}}\left(\boldsymbol{W}_{\boldsymbol{r}, \boldsymbol{i}_{\boldsymbol{r}}-1, \boldsymbol{j}_{\boldsymbol{r}}}^{\text {total }}\right)\right] \\
& \boldsymbol{T}_{\boldsymbol{r}, \boldsymbol{i}_{r}, \dot{j}_{r}}(0)=\delta\left[\boldsymbol{T}_{\boldsymbol{r}, \boldsymbol{i}_{r}-1, \boldsymbol{j}_{r}}\left(\boldsymbol{W}_{\boldsymbol{r}, \boldsymbol{i}_{r}-1, \boldsymbol{j}_{\boldsymbol{r}}}^{\text {total }}\right)\right] \\
& \operatorname{Press}_{\boldsymbol{r}, \boldsymbol{i}_{\boldsymbol{r}}, \boldsymbol{j}_{\boldsymbol{r}}}(0)=\delta\left[\operatorname{Press}_{\boldsymbol{r}, \boldsymbol{i}_{\boldsymbol{r}}-1, \boldsymbol{j}_{\boldsymbol{r}}}\left(\boldsymbol{W}_{\boldsymbol{r}, \boldsymbol{i}_{\boldsymbol{r}}-1, \boldsymbol{j}_{\boldsymbol{r}}}^{\text {total }}\right)\right]
\end{aligned}
$$


$\operatorname{Coke}_{r, i_{r}, j_{r}}(0)=\delta\left[\right.$ Coke $\left._{r, i_{r}, j_{r}-1}\left(W_{r, i_{r}, j_{r}-1}^{\text {total }}\right)\right]$

Here, the terms $\Omega_{i, j}($.$) and \Pi_{i, j}($.$) represent vectors of differential and algebraic equation in the$ reaction section, respectively. The vector $\Omega_{i, j}($.$) represents all the differential material and energy$ balances in the model. Moreover, the term $\Pi_{i, j}($.$) represents all equations for kinetic coefficients,$ as well as the expressions that define the reacting mixture properties, acid and metal adsorption functions, the fired heater energy balances, in addition to all other the balances at linking points of each reaction zone. The initial conditions for the reaction zone $i_{r}, j_{r}: \boldsymbol{F}_{\boldsymbol{c}, \boldsymbol{r}, \boldsymbol{i}_{r}, j_{r}}(0), \boldsymbol{T}_{\boldsymbol{r}, \boldsymbol{i}_{r}, j_{r}}(0)$, $\operatorname{Press}_{\boldsymbol{r}, \boldsymbol{i}_{\boldsymbol{r}}, \boldsymbol{j}_{\boldsymbol{r}}}(0)$, and Coke $_{\boldsymbol{r}, \boldsymbol{i}_{\boldsymbol{r}}, \boldsymbol{j}_{\boldsymbol{r}}}(0)$ are obtained from the material and energy balances $\delta($.$) at linking$ points that relate the outlet stream of reaction zone $i_{r}-1, j_{r}\left(\right.$ given by $\boldsymbol{F}_{\boldsymbol{c}, \boldsymbol{r}, \boldsymbol{i}_{r}, \boldsymbol{j}_{\boldsymbol{r}}}\left(\boldsymbol{W}_{\boldsymbol{r}, i_{r}-1, j_{r}}^{\text {total }}\right)$, $\boldsymbol{T}_{\boldsymbol{r}, \boldsymbol{i}_{\boldsymbol{r}}, \boldsymbol{j}_{\boldsymbol{r}}}\left(\boldsymbol{W}_{\boldsymbol{r}, \boldsymbol{i}_{\boldsymbol{r}}-1, \boldsymbol{j}_{\boldsymbol{r}}}^{\text {total }}\right), \boldsymbol{P}_{\boldsymbol{c}, \boldsymbol{r}, \boldsymbol{i}_{\boldsymbol{r}}, \boldsymbol{j}_{\boldsymbol{r}}}\left(\boldsymbol{W}_{\boldsymbol{r}, \boldsymbol{i}_{\boldsymbol{r}}-1, j_{\boldsymbol{r}}}^{\text {total }}\right)$ ), to the outlet stream of reaction zone $i_{r}, j_{r^{-}}-1$ (given by Coke $\left._{r, i_{r}, j_{r}-1}\left(\boldsymbol{W}_{\boldsymbol{r}, \boldsymbol{i}_{r}, j_{r}-1}^{\text {total }}\right)\right)$. Moreover, $\Psi$ are parameters that must be defined for entire reaction section, and must include kinetic rate constants, adsorption constants, and deactivation constants.

Once the overall reaction section model is defined, a proper objective function needs to be selected for parameter estimation. The model parameters $\Psi$ have been selected to minimize the deviation between the predicted and measured set of output variables, for this standard parameter estimation problem. Since this would entail the use of multiple data sets that describe how the different operating conditions can be related to the corresponding output variables, a large-scale reaction section model was defined for every data set $\boldsymbol{n} \in\left\{1, . ., \boldsymbol{N}_{\exp }\right\}$.

The least square differences (LSDs) method was used to evaluate the experimentally determined flowrates of components exiting the last reactor against those calculated from model, since the 
molar flowrates of all components at the outlet from the last reactor are known. Moreover, because the reformate composition was analyzed using the ASTM 5134 method, the overall paraffin composition for different carbon atoms has been measured. Hence, the normal and branched paraffins have been considered as one component, when specifying the number of carbon atoms. In order to evaluate the LSDs of the paraffin compositions which were measured experimentally against those calculated by the model, the quantity of normal and branched paraffins that are evaluated by model have to be summarized for each carbon number. Since the RON values for normal and branched paraffins are considerably different the LSD of RON has been introduced into objective function. The experimental RON number has been measured at the bottom of debutanizer column (C-101). To calculate the RON number using the model, a statistical function has been established, which basically determines how many components with four to six carbon atoms are in the reformate (S-57). It should be noted that components with more than six carbon atoms are always assumed to be present in the reformate stream (S-57). The LSDs for hydrogen and aromates have also been introduced into the objective function, because they are often considered major products of the CNR process, besides paraffins. LSDs values for naphthenes and olefins were not considered in this work, because their quantities have been reported to be very low. Last but not least, light gases LSDs have been introduced into objective function since they drastically affect the cracking reaction rates of paraffins.

As it has been mentioned earlier, the outlet compositions from the last reactor are the only known compositions, unlike the outlet compositions from the other reactors (which are unknown). Therefore, in order to account for those unknown concentrations, the LSDs for the outlet temperatures from each reactor, in addition to the heat required for the fired heaters, have all been introduced into the objective function. Moreover, in order to account for the coke 
formation reaction rate, the LSD for the catalyst coke concentration has also been introduced into objective function. Combining all the above information, the standard least-squared formulation for the objective function can be be stated as follows:

$$
\begin{aligned}
& \min _{\Psi} \sum_{n \in N_{\text {exp }}}\left(\text { out } \boldsymbol{F}_{H, r^{\text {rud }}, n}-\boldsymbol{F}_{H, n}^{M}\right) \mathbf{V}_{H_{2}}^{-1}\left(\boldsymbol{o u t} \boldsymbol{F}_{H, r^{\text {redu, }}, n}-\boldsymbol{F}_{H, n}^{M}\right)
\end{aligned}
$$

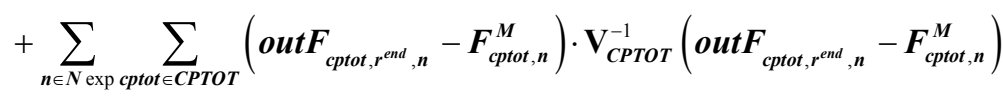

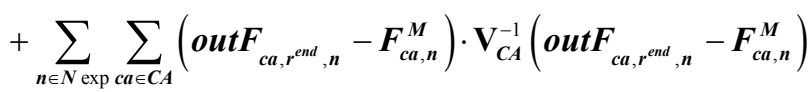

$$
\begin{aligned}
& +\sum_{n \in N \text { exp }} \sum_{r \in R x}\left(\text { out } \boldsymbol{T}_{r, n}-\boldsymbol{T}_{r, n}^{M}\right) \cdot \mathbf{V}_{T}^{-1}\left(\text { out } \boldsymbol{T}_{r, n}-\boldsymbol{T}_{r, n}^{M}\right) \\
& +\sum_{n \in N \text { exp }} \sum_{r \in R}\left(\text { outCoke }_{r, n}-\text { Coke }_{r, n}^{M}\right) \cdot \mathbf{V}_{C}^{-1}\left(\text { outCoke }_{r, n}-\text { Coke }_{r, n}^{M}\right) \\
& +\sum_{n \in N_{\text {exp }}}\left(\operatorname{RON}_{n}-\boldsymbol{R O N}_{n}^{M}\right) \mathbf{V}_{\text {RON }}^{-1}\left(\operatorname{RON}_{n}-\boldsymbol{R O N}_{n}^{M}\right) \\
& +\sum_{n \in N \text { exp }} \sum_{f h \in F H}\left(\boldsymbol{H}_{f l, n}-\boldsymbol{H}_{f h, n}^{M}\right) \cdot \mathbf{V}_{H T}^{-1}\left(\boldsymbol{H}_{f l, n}-\boldsymbol{H}_{f h, n}^{M}\right)
\end{aligned}
$$

Eq. (49) is the standard objective function where all model variables are matched with experimentally measured ones, except the term $\sum_{n \in N \text { exp }} \sum_{f h \in F H}\left(\boldsymbol{H}_{f h, n}-\boldsymbol{H}_{f h, n}^{M}\right) \cdot \mathbf{V}_{H}^{-1}\left(\boldsymbol{H}_{f h, n}-\boldsymbol{H}_{f h, n}^{M}\right) \cdot \boldsymbol{H}_{f h, n}^{M}$ is not directly measured, but rather calculated using the theoretical flame temperature, the amount of heat losses, and the amount of fuel consumed in each fired heater. The theoretical flame temperature and the mass flowrate of combustion products have been estimated by following the same procedure given by Smith ${ }^{43}$. The amount of excess air used, the air humidity, and the bridge wall temperature of a fired heater are also important, and have been accounted ${ }^{43} . \boldsymbol{H}_{f h, n}^{M}$ can be estimated using the following expression:

$$
\boldsymbol{H}_{f h, n}^{M}=\boldsymbol{m}_{c b, n} \int_{T_{b u, n}}^{T_{t r, n}} \sum_{c b \in C B} \boldsymbol{C} \boldsymbol{p}_{c b, n} d T
$$


The term $\sum_{n \in N \text { exp }} \sum_{f h \in F H}\left(\boldsymbol{H}_{f h, n}-\boldsymbol{H}_{f h, n}^{M}\right) \cdot \mathbf{V}_{H}^{-1}\left(\boldsymbol{H}_{f h, n}-\boldsymbol{H}_{f h, n}^{M}\right)$ accounts for the amount of fuel consumed in fired heaters. In addition, by matching $\boldsymbol{H}_{f h, n}$ and $\boldsymbol{H}_{f h, n}^{M}$ impact on kinetic parameters is established.

The general parameter estimation problem is defined by Eqs. (43 - 50). The fact that the overall reaction section model needs to be solved for every data set makes the problem rather complex. There are 126 unknown model parameters $\Psi$ of the reaction model which have been identified including: the reaction rate constants $\left(\right.$ Aref $_{r x}$, Eref $\left._{r x}\right)$, the adsorption acid function term constants $\left(K_{G}, K_{P}, K_{N}, K_{A}\right)$, the adsorption metal function term constants $\left(K_{6 N}, A_{m t}, H_{m t}\right)$, the coke formation

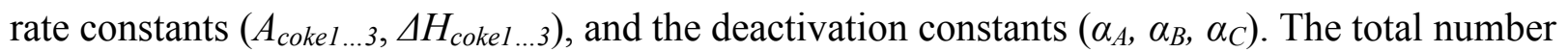
of experimental data sets which have been collected was found to be 47 sets, 44 of which were used for parameter estimation calculations, while 3 sets were used for model testing. Because 44 data sets have been used to estimate the unknown parameters, a maximum of 44 unknowns can be used by the model. Hence, it was found necessary to reduce the number of unknowns.

For this, it was assumed that reactions of the same type can use a single activation energy value. For example, one value for $\operatorname{Eref}_{r x}$ was utilized for the isomerization of n-paraffins, and the isomerization of single branch paraffins. The same approach was applied to cyclization reactions, naphthene isomerization reactions, dehydrogenation reactions of paraffins and aromatics, as well as the cracking reactions. Since the dehydrogenation reactions of paraffins and cyclohexanes are extremely fast, they were considered equilibrium reactions. Hence, their $A r e f_{r x}$ and $E r e f_{r x}$ values have been set in such a manner that equilibrium can be reached after the reactants are exposed to less than $10 \%$ of the reactor catalyst bed. This approach was utilized by Taskar and Riggis ${ }^{44}$. In addition, van Trimpont et al. reported that only single branch and multi branch paraffins can 
undergo cracking reactions in traceable amounts ${ }^{40}$. Therefore, it was assumed that normal paraffins do not undergo cracking reactions. Moreover, the adsorption acid function term constants $\left(K_{G}, K_{P}, K_{N}, K_{A}\right)$, the adsorption metal function term constants $\left(K_{6 N}, A_{m t}, H_{m t}\right)$, and the coke formation rate constants $\left(A_{\text {cokel ...3 }}, \Delta H_{\text {cokel ...3 }}\right)$ have not been estimated. Instead, those values have been taken from the kinetic study by van Trimpont et al. ${ }^{40}$. After applying all the aforementioned assumptions, the number of unknown parameters was reduced to 44 .

Once the parameters have been set, an appropriate solution strategy has to be defined. In general, there are two different strategies which can be adopted to solve differential algebraic equation constrained optimization problems: (1) the sequential or feasible - path approach, and (2) the simultaneous or infeasible - path approach ${ }^{19}$. In this study, adopting the simultaneous or infeasible path approach might lead to numerical difficulties that can be associated with the discretization of highly nonlinear and stiff differential algebraic equations problems ${ }^{19}$. Hence, the sequential approach has been selected instead, since it was reported to be more reliable for stiff nonlinear differential algebraic equations in comparisons with the simultaneous approach.

The solution strategy that was adopted for this differential algebraic equation problem can be described as follows: first off all, an initial guess for all unknown parameters is set. The inlet values of process variables can be obtained from the experimental measured data sets. Each reactor is split into 9 different reaction zones (three in each direction). The reaction zone balances have been described using Eqs. (15-17), and a solution to this system of ordinary differential equations can be obtained using the Gear method. The respective initial conditions for Eqs. (1517) have been described using Eqs. $(20,26,31)$. The process variables obtained by solving this first set of ordinary differential equations are then transferred to the next reaction zone, described by Eqs. $(22,28,33)$. The coke content in reaction zone is estimated using Eq.(18). The respective 
initial conditions for Eq. (18) has described using Eq.(37). This process is repeated until all the unknown variables for each of the reaction zones have been calculated. The process variables obtained from the reaction zone are then used for the fired heater calculations, where the temperature is increased. The required heating duty of a fired heater can be estimated using Eq. (42). The procedure is repeated for each reactor and fired heater in the reaction section. The estimated values of heat transferred by combustion can be evaluated using Eq. (50). The procedure is repeated using each of the 44 experimentally measured data sets described above, and the objective function is then calculated and optimized.

The Levenberg-Marquardt optimization method has been employed in this work, since it is capable of constantly updating the parameter values as this whole process is repeated, until a minimum objective value is reported ${ }^{45}$. The only problem with Levenberg-Marquardt optimization method is that the solutions reported for this highly nonlinear system of equations are often locally optimal, since they greatly depend on the initial guess which was utilized. To overcome this aspect, a multi-start search strategy (using 500 different staring points as initial guess points) was used to enable a global optimum or near global optimum solution to be reported. Moreover, the confidence interval of parameters has been estimated using the procedure given by Eglesious and Kalogerakis ${ }^{46}$.

\section{Modeling and Testing Results}

The values that have been obtained for the various estimated parameters together with their respective confidence intervals are presented in Table 6 . The CPU time of this parameter estimation strategy was reported to be 14 hours on a desktop PC with a 64-bit Operating System 
(2.7 GHz, 8.00 GB RAM), and an Intel ${ }^{\circledR}$ Core ${ }^{\mathrm{TM}}$ i7-2620M. This optimization problem was reported to be highly nonlinear since 209 different local minimums have been detected.

After completing this parameters estimation procedure, the model has been tested using three different sets of experimental data. It took less than $0.1 \mathrm{sec}$ to the simulate process using each data set, using the same desktop PC with a 64-bit Operating System (2.7 GHz, 8.00 GB RAM), and an Intel ${ }^{\circledR}$ Core ${ }^{\mathrm{TM}} \mathrm{i} 7-2620 \mathrm{M}$. The results of tests are summarized in Table 7.

Table 7. Component compositions predicted by the model (measured at the inlet and outlet of each reaction section)

Based on the results provided in Table 7, it can be noted that the model predictions, in terms of component compositions, have been found to be very close to the experimental data values, with exception of naphthenes. Since the concentrations of naphthenes were reported to be below 0.5 wt.\%, their impact was assumed to be negligible. Table 8 outlines the measured and calculated temperatures of each reactor outlet. The measured and calculated temperature values have been found to be in good agreement. Table 9 compares the measured and predicted heat duty values for the fired heaters. Likewise, the experimentally measured values and the model predicted values are in very good agreement.

Table 8. A comparison between the predicted and measured outlet temperatures from each reactor, at the given inlet reactor conditions ${ }^{\circ} \mathrm{C}$

Table 9. Predicted and measured heat duties at the inlet and outlet of each fired heater

In Figures 3-10 the relative absolute errors (RAEs) between the measured and model estimated variables for each experimental data set is illustrated. According to Figure 3, the RAEs for hydrogen in most experiments have been reported to be below 2 wt.\%. Light gases, paraffins, aromatics follow the same trend, as shown in Figures 4,5 and 6. The outlet temperature RAEs 
(Figure 7) have been found to be below $1 \%$ in most experiments. The same trend follows the required heat in fired heaters (Figure 8). The RAEs for RON number have been reported to be below $1.5 \%$ by most experiments (Figure 9). Additionally, the coke content RAEs in most experiments was below 3.5\% (Figure 10). Based on aforementioned, it can be concluded that the proposed model accurately predicts the behavior of real commercial CNR process, since the error range reported by most results is acceptable from the perspective of commercial utilization.

This model can further be improved if the number of unknown parameters is increased, and if an additional error-in-variables-measured formulation is employed ${ }^{19}$. This formulation mainly takes into account that various measurement errors can be associated with both the input and output variables in the least square formulation. In this study, only errors associated with the output variable measurements have been considered in the proposed least square formulation, due to lack of experimental data sets for input measurements. In addition, further model improvements may entail the use of deterministic or stochastic solvers that could assist in obtaining a global optimum solution more efficiently, such as: Baron ${ }^{47}$, Antigona ${ }^{48}$, Genetic Algorithm ${ }^{49}$ etc.

Figure 3. RAEs for the hydrogen predicted values from different experimental data sets

Figure 4. RAEs for the light gas predicted values from different experimental data sets

Figure 5. RAEs for the paraffin predicted values from different experimental data sets

Figure 6. RAEs for the aromatics predicted values from different experimental data sets 
Figure 7. RAEs for the outlet reactor temperature predicted values from different experimental data sets

Figure 8. RAEs for the predicted fired heater duties from different experimental data sets

Figure 9. RAEs for RON predicted values from different experimental data sets

Figure 10. RAEs for coke predicted values from different experimental data sets

\section{Conclusion}

This work presents a mathematical model which has been developed to predict the behavior of the reaction section of a commercial CCR process. CCR involves a feedstock stream that is a blend of straight run naphtha and gasoline produced from a Vacuum Gas Oil Hydrocracking Unit and a Vacuum Residue Hydrocracking Unit. The model consists of a kinetic set of equations that are combined to a set of equations that describe the reactor equipment (mainly for moving bed reactors and fired heaters). The kinetic model which has been used in this work is an upgraded version of the model presented by Marin et al ${ }^{39}$, and van Trimpont et al $^{40}$. The moving bed reactors were modeled using the "quasi-steady state" approach proposed by Stijepovic et al ${ }^{42}$. The fired heaters have been modeled using the energy and material balances obtained from the process and utility side. Combining all this information resulted in an overall model which consists of 126 unknown parameters. The number of unknown parameters was reduced to 44, after applying several assumptions. The sequential, or feasible - path approach has been used to carry out the parameter estimation procedure, while the Levenberg-Marquardt optimization method with multi starting features was employed to determine a global optimum solution. The estimated parameters obtained from the model have been tested against 3 different sets of experimental data. The model predictions were found to be in good agreement with the 
experimental data. The relative absolute errors (RAEs) between the measured and model estimated variables have been found to be lower than $2 \%$ in the most cases. The RAE associated with the required fired heater duties were less than $1.0 \%$. Simulating the reaction section of the CCR process required less than 0.1 seconds of CPU time, which clearly indicates that this model can be very suitable for carrying out optimization studies. Moreover, this study shows that although there is fluctuation in composition of feedstock, lumped kinetic approach was capable to well predict behavior of CCR process.

\title{
Acknowledgments
}

\begin{abstract}
Aleksandar Grujić and Mirko Stijepović are grateful to Ministry of Education, Science and Technological Development Republic of Serbia (project III 45019, TR 34011, OI 172063) for support.
\end{abstract}




\section{Nomenclature}

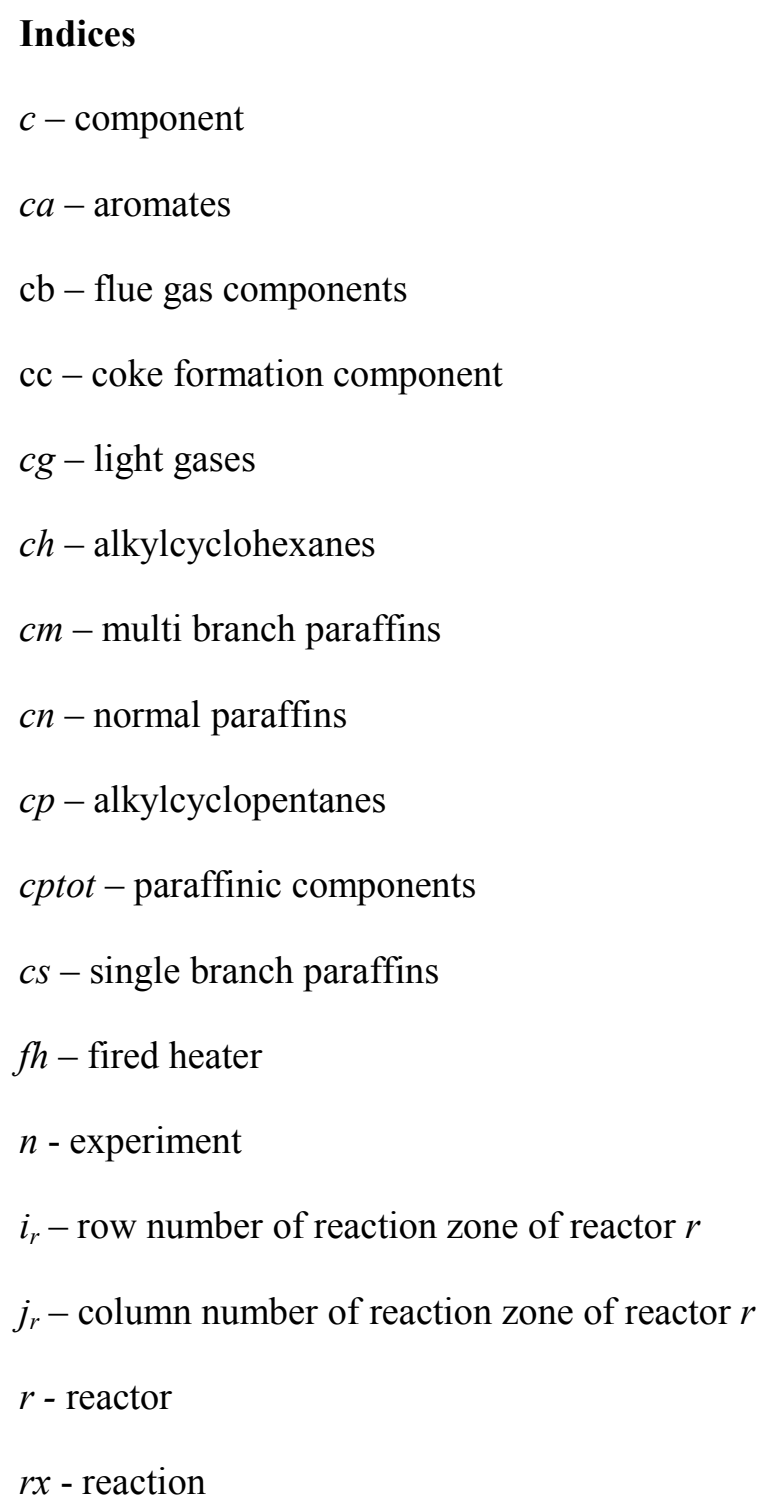




$$
\begin{aligned}
& C A \text { - set of aromate components } \\
& C B \text { - set of flue gas components } \\
& \text { CC - set coke formation components } \\
& C G \text { - set of light gases components } \\
& C H \text { - set of alkylcyclohexane components } \\
& C M-\text { set of multu branch paraffin components } \\
& C N-\text { set of normal paraffin components } \\
& C P-\text { set of alkylcyclopentane components } \\
& C P T O T \text { - set of paraffinic components } \\
& C S-\text { set of single branch paraffin components } \\
& \text { FH - set of fired heaters } \\
& \mathrm{N}-\text { set of experiments } \\
& I_{r}-\text { set of rows in reactor } r \\
& J_{r}-\text { set of rows in reactor } r \\
& R c-\text { set of reactors } \\
& R x-\text { set of reactions }
\end{aligned}
$$

\section{Parameters}

$\alpha_{A}, \alpha_{C}, \alpha_{M}$ - deactivation constants for acid, coke and metal $\left(\mathrm{kg}_{\text {cat }} / \mathrm{kg}_{\text {coke }}\right)$

$\beta_{r x}$ - reaction $r x$ is catalyzed by: acid function - 1 , metal function - 0

$\Delta \boldsymbol{H r x n} \boldsymbol{n}_{r x}^{o}$ - heat of reaction of reaction $r x$ at temperature $\mathrm{T}_{r e f}(\mathrm{~kJ} / \mathrm{mol})$

$\Delta p_{\text {const }}$ - constant pressure drop (bar $\left./ \mathrm{kg}_{\text {cat }}\right)$

$\zeta_{r x}$ - reaction $r x$ is used in calculation: used $=1$, not used $=0$

$\boldsymbol{A}_{\text {cokel }}, \boldsymbol{A}_{\text {coke } 2}, \boldsymbol{A}_{\text {coke3 } 3}$ - coke formation reaction rate constants $\left(\mathrm{kmol} / \mathrm{kg}_{\mathrm{cat}} / \mathrm{h}\right)$

$A_{m t}$ - constant of adsorption term for metal function (bar) 
Aref $_{r x}$ - reaction $r x$ constant

Coke $\boldsymbol{e}_{r, n}^{M}$ - measured coke concentration from last reactor of data set $n\left(\mathrm{~kg}_{\text {coke }} / \mathrm{kg}_{\text {cat }}\right)$

$\boldsymbol{E} \boldsymbol{a}_{\text {coke } 1}, \boldsymbol{E} \boldsymbol{a}_{\text {coke } 2}, \boldsymbol{E} \boldsymbol{a}_{\text {coke } 3}-$ coke formation reaction rate constants $(\mathrm{kJ} / \mathrm{mol})$

Eref $_{r x}$ - activation energy of reaction $r x(\mathrm{~kJ} / \mathrm{mol})$

$\boldsymbol{F}_{c, n}^{M}$ - measured flowrate of component $c$ from last reactor of data set $n(\mathrm{kmol} / \mathrm{hr})$

$\boldsymbol{H}_{f h, n}^{M}$ - estimated heat required to rise temperature in fired heater $f h$ for data set $n(\mathrm{~kJ} / \mathrm{h})$

$H_{m t}$ - constant of adsorption term for metal function $(\mathrm{kJ} / \mathrm{mol})$

$K_{6 N}$ - constant of adsorption term for metal function for alkylcyclohexanes $\left(\right.$ bar $\left.^{-1}\right)$

$K_{A}$ - constant of adsorption term for acid function for aromates $\left(\mathrm{bar}^{-1}\right)$

$K_{G}-$ constant of adsorption term for acid function for light gases

$K_{N}$ - constant of adsorption term for acid function for naphthenes

$K_{P}-$ constant of adsorption term for acid function for paraffins

$\boldsymbol{K r e f}_{r x}$ - constant in backward reaction rate coefficient $\left(1 / \boldsymbol{b a r}^{\nu^{\nu r o d} d_{c, r x}-\text { rreak }_{c, r x}}\right)$

$\boldsymbol{m}_{c b, n}$ - mass flowrate of combustion products $(\mathrm{kg} / \mathrm{hr})$

Press $_{r, n}^{M}$ - measured outlet pressure from reactor $r$ of data set $n$ (bar)

$r^{\text {end }}-$ number of reactors

$\boldsymbol{R}_{\text {gas }}$ - universal gas constant $(\mathrm{kJ} / \mathrm{mol} / \mathrm{K})$

$\boldsymbol{R O N}_{c}$ - research octane number of component c

$r N_{r}--$ total number of columns in reactor $r$

$T_{b w}$ - bridge wall temperature (K)

$\boldsymbol{T}_{\text {ref }}$ - reference temperature $(\mathrm{K})$

$\boldsymbol{T}_{r, n}^{M}$ - measured outlet temperature from reactor $r$ of data set $n(\mathrm{~K})$

$T_{t f t}$ - theoretical flame temperature (K)

$U_{t}-$ circulation rate of catalyst $\left(\mathrm{kg}_{\mathrm{cat}} / \mathrm{h}\right)$ 
$\mathbf{V}_{\boldsymbol{H}_{2}}^{-1}, \mathbf{V}_{\text {CPTOT }}^{-1}, \mathbf{V}_{\boldsymbol{C A}}^{-1}, \mathbf{V}_{\boldsymbol{T}}^{-1}, \mathbf{V}_{\boldsymbol{C}}^{-1}, \mathbf{V}_{\boldsymbol{R} \boldsymbol{N}}^{-1}$ and $\mathbf{V}_{\boldsymbol{H} \boldsymbol{T}}^{-1}$ - denote positive defined weighting matrices for the output variables

$\operatorname{pprod}_{c, r x}$ - stoichiometric coefficient of product $c$ in reaction $r x$

$\boldsymbol{v r e a k}_{c, r x}$ - stoichiometric coefficient of reactant $c$ in reaction $r x$

$W_{r, i_{r}, j_{r}}^{\text {total }}$ - total catalyst load on reaction zone $i_{r}, j_{r}$ in reactor $r\left(\mathrm{~kg}_{\mathrm{cat}}\right)$

$z N_{r}-$ total number of rows in reactor $r$

\author{
Variables \\ $\gamma_{r, i_{r}, j_{r}}$ - adsorption term for acid function of reactor $r$ in reaction zone $i_{r}, j_{r}$ \\ $\theta_{r, i_{r}, j}$ - adsorption term for metal function of reactor $r$ in reaction zone $i_{r}, j_{r}$ \\ $\Delta \boldsymbol{H r x n}_{r x, r, i_{r}, j_{r}}$ - heat of reaction $r x$ in reaction zone $i_{r,} j_{r}$ of reactor $r(\mathrm{~kJ} / \mathrm{kmol})$ \\ $\Delta \boldsymbol{H r x n}_{\text {coke, }, \boldsymbol{i}_{r}, j_{r}}$ - heat of coke formation in reaction zone $i_{r, j_{r}}$ of reactor $r(\mathrm{~kJ} / \mathrm{kmol})$ \\ $\phi_{A, r, i_{r}, j_{r}}$ - deactivation function of acid site of reaction $r x$ in reaction zone $i_{r}, j_{r}$ of reactor $r$ \\ $\phi_{c o k e, r, i_{r}, j_{r}}$ - deactivation function of coke reaction in reaction zone $i_{r} j_{r}$ of reactor $r$ \\ $\phi_{M, r, i_{r}, j_{r}}$ - deactivation function of metal site of reaction $r x$ in reaction zone $i_{r} j_{r}$ of reactor $r$ \\ $\phi_{r x, r, i_{r}, j_{r}}$ - deactivation function of reaction $r x$ in reaction zone $i_{r} j_{r}$ of reactor $r$ \\ Cok $_{r, i_{r}, j_{r}}-$ coke content $\left(\mathrm{kg}_{\mathrm{coke}} / \mathrm{kg}_{\mathrm{cat}}\right)$ \\ $\operatorname{Cok}_{r, i_{r}, j_{r}}^{i n}$ - inlet coke content in each reaction zone $\left(\mathrm{kg}_{\text {coke }} / \mathrm{kg}_{\mathrm{cat}}\right)$ \\ Coke $_{r, i_{r}, j_{r}}^{\text {out }}$ - outlet coke content from each reaction zone $\left(\mathrm{kg}_{\text {coke }} / \mathrm{kg}_{\text {cat }}\right)$ \\ $\boldsymbol{C p}_{c b}$ - heat capacity of flue gas component $c b(\mathrm{~kJ} / \mathrm{kg})$ \\ $\boldsymbol{C}_{\boldsymbol{c}, \boldsymbol{r}, \boldsymbol{i}_{\boldsymbol{r}}, \boldsymbol{j}_{\boldsymbol{r}}}$ - heat capacity of component $c$ in reactor $r$ in reaction zone $i_{r}, j_{r}(\mathrm{~kJ} / \mathrm{Kmol} / \mathrm{K})$ \\ $\boldsymbol{F}_{\boldsymbol{c}, \boldsymbol{r}, \boldsymbol{i}_{r}, j_{r}}-$ molar flowrate of component $c$ in reactor $r$ in reaction zone $i_{r}, j_{\mathrm{r}}(\mathrm{kmol} / \mathrm{hr})$
}


$F_{c, r, i_{r}, j_{r}}^{i n}$ - inlet molar flow rate of component $\mathrm{c}$ in reactor $\mathrm{r}$ of reaction zone $i_{r}, j_{r}(\mathrm{kmol} / \mathrm{hr})$

$\boldsymbol{F}_{\boldsymbol{c}, \boldsymbol{r}, \boldsymbol{i}_{r}, j_{r}}^{\text {out }}$ - outlet molar flow rate of component $c$ in reactor $r$ of reaction zone $i_{r}, j_{r}(\mathrm{kmol} / \mathrm{hr})$

$\boldsymbol{H c o m p}_{c c, r, i_{r}, j_{r}}$ - heat of formation for component cc in reaction zone $i_{r}, j_{r}$ of reactor $r(\mathrm{~kJ} / \mathrm{kmol})$

$\boldsymbol{H}_{\boldsymbol{c o m p}} \boldsymbol{p}_{\text {coke, }, \boldsymbol{i}_{r}, j_{r}}$ - heat of formation for coke in reaction zone $i_{r}, j_{r}$ of reactor $r(\mathrm{~kJ} / \mathrm{kmol})$

$\boldsymbol{H c o m p}_{\boldsymbol{c}, \boldsymbol{r}, \boldsymbol{i}_{r}, j_{r}}$ - heat of formation for component c in reaction zone $i_{r}, j_{r}$ of reactor $r(\mathrm{~kJ} / \mathrm{kmol})$

$\boldsymbol{H}_{f h}$ - heat required in fired heater $f h(\mathrm{~kW})$

inCoke $\boldsymbol{~}_{\boldsymbol{r}}$ - inlet coke concentration in reactor $r\left(\mathrm{~kg}_{\text {coke }} / \mathrm{kg}_{\text {cat }}\right)$

in $\boldsymbol{F}_{c, r}$ - inlet flowrate of component $c$ in reactor $r(\mathrm{kmol} / \mathrm{hr})$

inPress $_{r}$ - inlet pressure in reactor $r$ (bar)

$\boldsymbol{i n} \boldsymbol{T}_{\boldsymbol{r}}$ - inlet temperature in reactor $r(\mathrm{~K})$

$\boldsymbol{k}_{\boldsymbol{B} r x, r, i_{r}, j_{r}}$ - backward reaction rate coefficient of reaction $r x$ of reactor $r$ in reaction zone $i_{r}, j_{r}$ $\left(1 / \boldsymbol{b a r}^{v \text { prod }_{c, r x}-\text { vreak }_{c, r x}}\right)$

$\boldsymbol{k}_{\text {cokel, },, \boldsymbol{i}_{r}, j}, \boldsymbol{k}_{\text {coke } 2, r, i_{r}, j}, \boldsymbol{k}_{\text {coke } 3, r, i_{r}, j}$ - reaction rate coefficient for coke formation reaction in reactor $r$ $\left(\mathrm{kmol} / \mathrm{kg}_{\mathrm{cat}} / \mathrm{h}\right)$

$\boldsymbol{k}_{F r x, r, i_{r}, j_{r}}$ - forward reaction rate coefficient of reaction $r x$ of reactor $r$ in reaction zone $i_{r}, j_{r}$ $\left(\boldsymbol{k m o l} / \boldsymbol{k g}_{\text {cat }} / \mathrm{bar}^{\text {vreak }} \boldsymbol{k}_{c, r x}\right)$

$\boldsymbol{m}_{\text {feedstock }}$ - mass flowrate of feedstock $(\mathrm{kg} / \mathrm{h})$

$\boldsymbol{m}_{F G}$ - mass flowrate of fuel gas $(\mathrm{kg} / \mathrm{h})$

$\boldsymbol{m}_{\boldsymbol{L P G}}$ - mass flowrate of LPG $(\mathrm{kg} / \mathrm{h})$

$\boldsymbol{m}_{\text {net_ } \boldsymbol{H}}$ - mass flowrate of rich hydrogen $\operatorname{stream}(\mathrm{kg} / \mathrm{h})$

$\boldsymbol{m}_{\text {reforamte }}$ - mass flowrate of reformate $(\mathrm{kg} / \mathrm{h})$

outCoke $\boldsymbol{~}_{r}$ - outlet coke concentration in reactor $r\left(\mathrm{~kg}_{\text {coke }} / \mathrm{kg}_{\text {cat }}\right)$

$\boldsymbol{o u t F}_{c, \boldsymbol{r}}$ - outlet flowrate of component $c$ in reactor $r(\mathrm{kmol} / \mathrm{hr})$ 
outPress $_{r}$ - outlet pressure in reactor $r$ (bar)

$\boldsymbol{o u t}_{\boldsymbol{r}}$ - outlet temperature in reactor $r(\mathrm{~K})$

$\boldsymbol{P}_{c, r, i_{r}, j_{r}}$ - partial pressure of component $c$ in reactor $r$ in reaction zone $i_{r} j_{r}$

$\boldsymbol{P}_{\boldsymbol{H}, i_{r}, j_{r}}$ - partial pressure of component hydrogen of reactor $r$ in reaction zone $i_{r} j_{r}$

$\boldsymbol{P r e s s}_{r, i_{r}, j_{r}}$ - total pressure in reaction zone $i_{r}, j_{r}$ of reactor $r$ (bar)

$\boldsymbol{P r e s s}_{\boldsymbol{r}, i_{r}, j_{r}}^{i{ }_{i}}$ - inlet pressure of reaction zone $i_{r}, j_{r}$ of reactor $r$ (bar)

$\operatorname{Press}_{r, i_{r}, j_{r}}^{\text {out }}$ - outlet pressure of reaction zone $i_{r} j_{r}$ of reactor $r$ (bar)

$r_{c, r, i_{r}, j_{r}}$ - reaction rate of component $c$ of reaction zone $i_{r} j_{r}$ of reactor $r$

$\boldsymbol{R}_{\text {coke }, \boldsymbol{r}, \boldsymbol{i}_{r}, j}$ - reaction rate of coke formation with catalyst deactivation $\left(\mathrm{kmol} / \mathrm{kg}_{\mathrm{cat}} / \mathrm{h}\right)$

$\boldsymbol{R}_{\text {coke, }, i_{r}, j}^{0}$ - reaction rate of coke formation without catalyst deactivation $\left(\mathrm{kmol} / \mathrm{kg}_{\mathrm{cat}} / \mathrm{h}\right)$

$\boldsymbol{r x n}^{\boldsymbol{o}}{ }_{r x, r, i_{r}, j_{r}}$ - rate of reaction $r x$ in reactor $r$ in reaction zone $i_{r}, j_{r}\left(\mathrm{kmol} / \mathrm{kg}_{\mathrm{cat}} / \mathrm{h}\right)$

$\boldsymbol{T}_{r, i_{r}, j_{r}}$ - temperature in reaction zone $i_{r}, j_{r}$ of reactor $r(\mathrm{~K})$

$T_{\boldsymbol{r}, i_{r}, j_{r}}^{i{ }_{r}}$ - inlet temperature of reaction zone $i_{r}, j_{r}$ of reactor $r(\mathrm{~K})$

$T_{r, i_{r}, j_{r}}^{\text {out }}$ - outlet temperature of reaction zone $i_{r}, j_{r}$ of reactor $r(\mathrm{~K})$

$\boldsymbol{w}_{\boldsymbol{H}}^{\text {feedstock }}$ - weight fraction of hydrogen in feedstock

$\boldsymbol{w}_{\boldsymbol{H}}^{F G}$ - weight fraction of hydrogen in fuel gas

$\boldsymbol{w}_{\boldsymbol{H}}^{\boldsymbol{L P G}}$ - weight fraction of hydrogen in LPG

$\boldsymbol{w}_{\boldsymbol{H}}^{\text {net }{ }_{-} \boldsymbol{H}}$ - weight fraction of hydrogen in rich hydrogen stream

$\boldsymbol{w}_{\boldsymbol{H}}^{\text {reformate }}$ - weight fraction of hydrogen in reformate

$\boldsymbol{W}_{\boldsymbol{r}, \boldsymbol{i}_{r}, \boldsymbol{j}_{\boldsymbol{r}}}$ - catalyst load of reaction zone $i_{r}, j_{r}$ in reactor $r$ 


\section{References}

1. Antos, G. J.; Aitani, A. M., Catalytic Naphtha Reforming, Revised and Expanded. CRC Press: New York, 2004.

2. Lapinski, M. P.; Metro, S.; Pujadó, P. R.; Moser, M., Catalytic Reforming in Petroleum Processing. In Handbook of Petroleum Processing, Treese, S. A.; Jones, D. S., Eds. Springer: 2015; pp 229-260.

3. $\quad$ Speight, J. G.; Ozum, B., Petroleum refining processes. CRC Press: 2001.

4. Speight, J. G., The Chemistry and Technology of Petroleum, Fifth Edition. Taylor \& Francis: 2014.

5. Moser, M.; Sadler, C., Reforming - industrial. In Encyclopedia of Catalysis, Müller, T.; Horváth, J., Eds. Wiley, New York: 2010.

6. Anderson, J. R.; Boudart, M., Catalysis: science and technology. Springer Science \& Business Media: 2012; Vol. 11.

7. Martino, G., Catalytic Reforming. In Petroleum Refining. Vol. 3 Conversion Processes, Leprince, P., Ed. Editions Technip: 2001; Vol. 3.

8. Pashikanti, K.; Liu, Y. A., Predictive Modeling of Large-Scale Integrated Refinery Reaction and Fractionation Systems from Plant Data. Part 3: Continuous Catalyst Regeneration (CCR) Reforming Process. Energy \& Fuels 2011, 25, (11), 5320-5344.

9. Domergue, B.; le Goff, P.-Y., Octanizing reformer options. Petroleum technology quarterly 2006, $11,(1), 67-73$.

10. Mostafazadeh, A. K.; Rahimpour, M. R., A membrane catalytic bed concept for naphtha reforming in the presence of catalyst deactivation. Chemical Engineering and Processing 2009, 48, (2), 683-694.

11. Iranshahi, D.; Pourazadi, E.; Paymooni, K.; Bahmanpour, A. M.; Rahimpour, M. R.; Shariati, A., Modeling of an axial flow, spherical packed-bed reactor for naphtha reforming process in the presence of the catalyst deactivation. International Journal of Hydrogen Energy 2010, 35, (23), 12784-12799.

12. Iranshahi, D.; Rahimpour, M. R.; Asgari, A., A novel dynamic radial-flow, spherical-bed reactor concept for naphtha reforming in the presence of catalyst deactivation. International Journal of Hydrogen Energy 2010, 35, (12), 6261-6275.

13. Rahimpour, M. R.; Iranshahi, D.; Bahmanpour, A. M., Dynamic optimization of a multi-stage spherical, radial flow reactor for the naphtha reforming process in the presence of catalyst deactivation using differential evolution (DE) method. International Journal of Hydrogen Energy 2010, 35, (14), 7498-7511.

14. Rahimpour, M. R.; Iranshahi, D.; Pourazadi, E.; Paymooni, K., Evaluation of Optimum Design Parameters and Operating Conditions of Axial- and Radial-Flow Tubular Naphtha Reforming Reactors, Using the Differential Evolution Method, Considering Catalyst Deactivation. Energy \& Fuels 2011, 25, (2), 762-772.

15. Rahimpour, M. R.; Jafari, M.; Iranshahi, D., Progress in catalytic naphtha reforming process: A review. Applied Energy 2013, 109, 79-93.

16. Saeedi, R.; Iranshahi, D., Multi-objective optimization of thermally coupled reactor of CCR naphtha reforming in presence of $\mathrm{SO} 2$ oxidation to boost the gasoline octane number and hydrogen. Fuel 2017, 206, 580-592.

17. Poparad, A.; Ellis, B.; Glover, B.; Metro, S., Reforming solutions for improved profits in an updown world. UOP Manual 2011.

18. Stijepovic, V.; Linke, P.; Alnouri, S.; Kijevcanin, M.; Grujic, A.; Stijepovic, M., Toward enhanced hydrogen production in a catalytic naphtha reforming process. International Journal of Hydrogen Energy 2012, 37, (16), 11772-11784.

19. Zavala, V. M.; Biegler, L. T., Large-scale parameter estimation in low-density polyethylene tubular reactors. Industrial \& Engineering Chemistry Research 2006, 45, (23), 7867-7881. 
20. Chang, A. F.; Pashikanti, K.; Liu, Y., Predictive Modeling of the Continuous Catalyst Regeneration (CCR) Reforming Process. In Refinery Engineering: Integrated Process Modeling and Optimization, Wiley-VCH Verlag \& Co. KGaA: Germany, 2012; pp 253-361.

21. Hou, W. F.; Su, H. Y.; Hu, Y. Y.; Chu, J., Modeling, simulation and optimization of a whole industrial catalytic naphtha reforming process on aspen plus platform. Chinese Journal of Chemical Engineering 2006, 14, (5), 584-591.

22. Iranshahi, D.; Karimi, M.; Amiri, S.; Jafari, M.; Rafiei, R.; Rahimpour, M. R., Modeling of naphtha reforming unit applying detailed description of kinetic in continuous catalytic regeneration process. Chemical Engineering Research \& Design 2014, 92, (9), 1704-1727.

23. Lee, J. W.; Ko, Y. C.; Jung, Y. K.; Lee, K. S.; Yoon, E. S., A modeling and simulation study on a naphtha reforming unit with a catalyst circulation and regeneration system. Computers \& Chemical Engineering 1997, 21, S1105-S1110.

24. Bommannan, D.; Srivastava, R.; Saraf, D., Modelling of catalytic naphtha reformers. The Canadian Journal of Chemical Engineering 1989, 67, (3), 405-411.

25. Padmavathi, G.; Chaudhuri, K. K., Modelling and simulation of commercial catalytic naphtha reformers. Canadian Journal of Chemical Engineering 1997, 75, (5), 930-937.

26. Ancheyta, J., Modeling of Catalytic Reforming. In Modeling and Simulation of Catalytic Reactors for Petroleum Refining, John Wiley \& Sons: New Jersey, 2011; pp 313-367.

27. Sotelo-Boyas, R.; Froment, G. F., Fundamental Kinetic Modeling of Catalytic Reforming. Industrial \& Engineering Chemistry Research 2009, 48, (3), 1107-1119.

28. Quann, R. J.; Jaff, S. B., Building useful models of complex reaction systems in petroleum refining. Chemical Engineering Science 1996, 51, (10), 1615-\&.

29. Wei, W.; Bennett, C. A.; Tanaka, R.; Hou, G.; Klein, M. T., Detailed kinetic models for catalytic reforming. Fuel Processing Technology 2008, 89, (4), 344-349.

30. Wei, W.; Bennett, C. A.; Tanaka, R.; Hou, G.; Klein, M. T.; Klein, M. T., Computer aided kinetic modeling with KMT and KME. Fuel Processing Technology 2008, 89, (4), 350-363.

31. Turpin, L., Cut benzene out of reformate. Hydrocarbon processing 1992, 71, (6), 81-92.

32. Group, M. https://molgroup.info/en/

33. ASTM, D5134-98: Standard Test Method for Detailed Analysis of Petroleum Naphthas through n-Nonane by Capillary Gas Chromatography. American Society for Testing and Materials West Conshohocken,PA, 1999.

34. ASTM, D6839-02, Standard Test Method for Hydrocarbon Types, Oxygenated Compounds and Benzene in Spark Ignition Engine Fuels by Gas Chromatography, ASTM International, West Conshohocken, PA, 2002. In American Society for Testing and Materials West Conshohocken, PA, 2008. 35. ASTM, UOP539-97, Refinery Gas Analysis by GC. American Society for Testing and Materials West Conshohocken, PA, 1997.

36. Standardization, I. O. f., EN 27941, Commercial Propane and Butane-Analysis by Gas Chromatography, . ISO: 1988.

37. ASTM, D5373 - 14, Standard Test Methods for Determination of Carbon, Hydrogen and Nitrogen in Analysis Samples of Coal and Carbon in Analysis Samples of Coal and Coke. American Society for Testing and Materials West Conshohocken, PA, 2015.

38. Jenkins, J.; Stephens, T., Kinetics of cat reforming. Hydrocarbon processing 1980, 60, (11), 163 167.

39. Marin, G.; Froment, G., Reforming of C6 hydrocarbons on a Pt $\square$ Al2O3 catalyst. Chemical Engineering Science 1982, 37, (5), 759-773.

40. Van Trimpont, P.; Marin, G.; Froment, G., Reforming of C7 hydrocarbons on a sulfided commercial platinum/alumina catalyst. Industrial \& engineering chemistry research 1988, 27, (1), 51-57.

41. White, W. B.; Johnson, S. M.; Dantzig, G. B., Chemical equilibrium in complex mixtures. The Journal of Chemical Physics 1958, 28, (5), 751-755.

42. Stijepovic, M. Z.; Linke, P.; Kijevcanin, M., Optimization Approach for Continuous Catalytic Regenerative Reformer Processes. Energy \& Fuels 2010, 24, (3), 1908-1916. 
43. Smith, R., Chemical process: design and integration. John Wiley \& Sons: 2005.

44. Taskar, U.; Riggs, J. B., Modeling and optimization of a semiregenerative catalytic naphtha reformer. Aiche Journal 1997, 43, (3), 740-753.

45. Moré, J. J., The Levenberg-Marquardt algorithm: implementation and theory. In Numerical analysis, Springer: 1978; pp 105-116.

46. $\quad$ Englezos, P.; Kalogerakis, N., Applied parameter estimation for chemical engineers. Marcel Dekker, Inc.: New York, 2001.

47. Tawarmalani, M.; Sahinidis, N. V., A polyhedral branch-and-cut approach to global optimization. Mathematical Programming 2005, 103, (2), 225-249.

48. Misener, R.; Floudas, C. A., ANTIGONE: algorithms for continuous/integer global optimization of nonlinear equations. Journal of Global Optimization 2014, 59, (2-3), 503-526.

49. Conn, A.; Gould, N.; Toint, P., A globally convergent Lagrangian barrier algorithm for optimization with general inequality constraints and simple bounds. Mathematics of Computation of the American Mathematical Society 1997, 66, (217), 261-288. 


\section{List of Tables}

Table 1. Range of operating conditions

Table 2. Composition ranges of feedstock and reformate in $\mathrm{wt} \%$

Table 3 Composition ranges of recycle gas, net hydrogen, LPG and fuel gas in mol \%

Table 4. Composition ranges of coke before and after regeneration

Table 5. List of pure components and pseudo-components

Table 6 Proposed kinetics model and kinetic parameters

Table 7. Component compositions predicted by the model (measured at the inlet and outlet of each reaction section)

Table 8. A comparison between the predicted and measured outlet temperatures from each reactor, at the given inlet reactor conditions ${ }^{\circ} \mathrm{C}$

Table 9. Predicted and measured heat duties at the inlet and outlet of each fired heater 


\section{List of Figures}

Figure 1. CCR Process Flowsheet

Figure 2. a) Moving bed radial flow reactor, b) Layers of moving bed, c) Reaction zones

Figure 3. RAEs for the hydrogen predicted values from different experimental data sets

Figure 4. RAEs for the light gas predicted values from different experimental data sets

Figure 5. RAEs for the paraffin predicted values from different experimental data sets

Figure 6. RAEs for the aromatics predicted values from different experimental data sets

Figure 7. RAEs for the outlet reactor temperature predicted values from different experimental data sets

Figure 8. RAEs for the predicted fired heater duties from different experimental data sets

Figure 9. RAEs for RON predicted values from different experimental data sets

Figure 10. RAEs for coke predicted values from different experimental data sets 


\section{Figures}

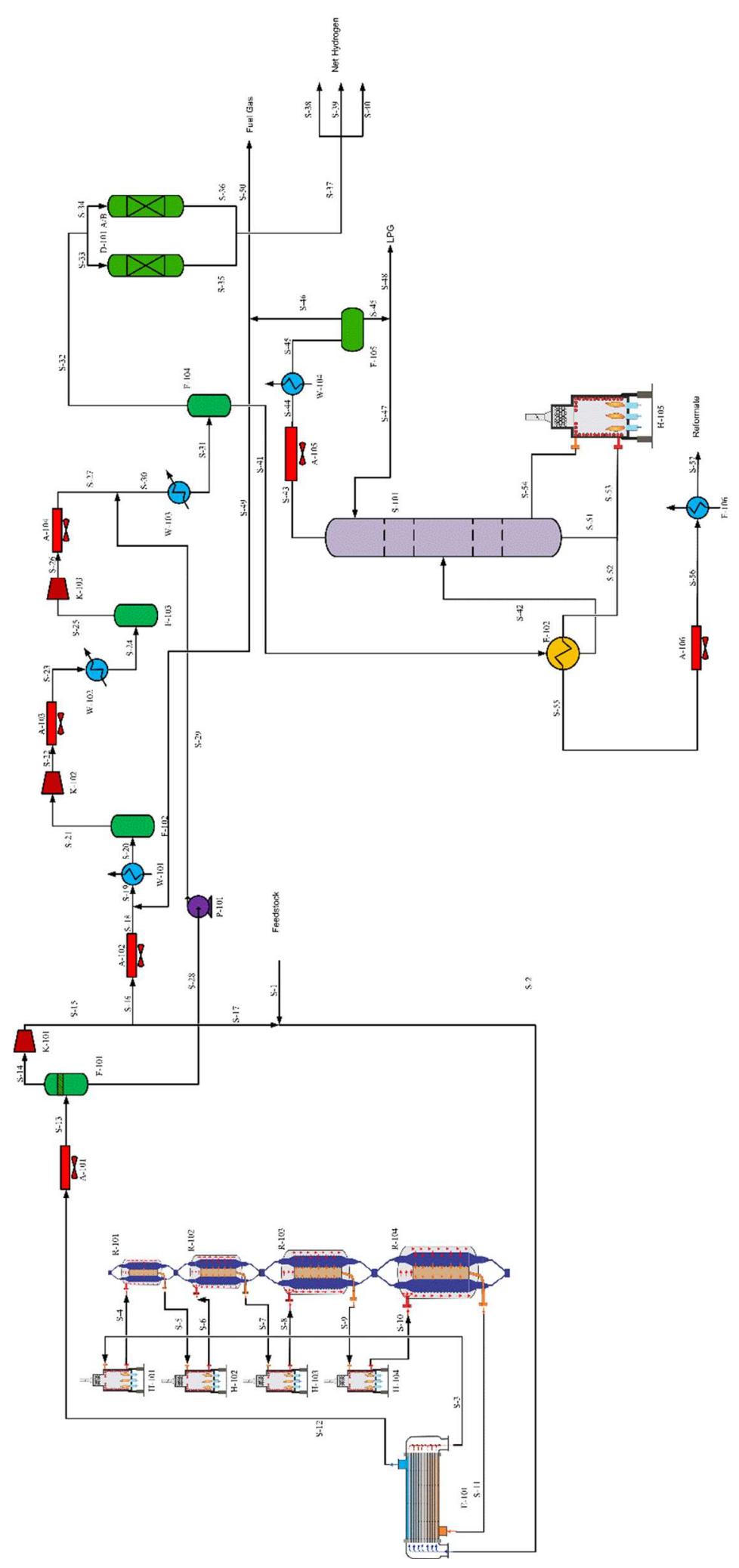

Figure 1. CCR Process Flowsheet 


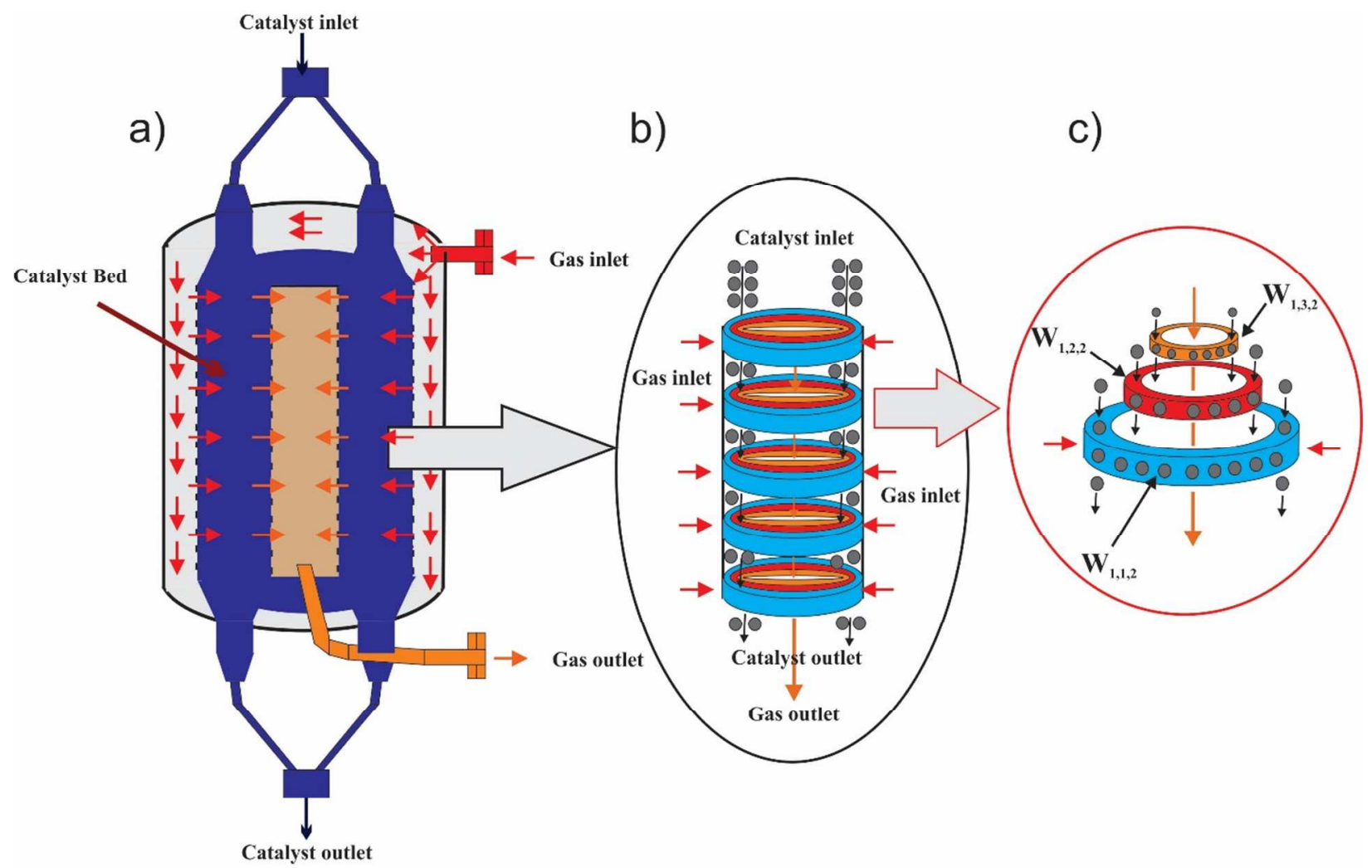

Figure 2. a) Moving bed radial flow reactor, b) Layers of moving bed, c) Reaction zones 


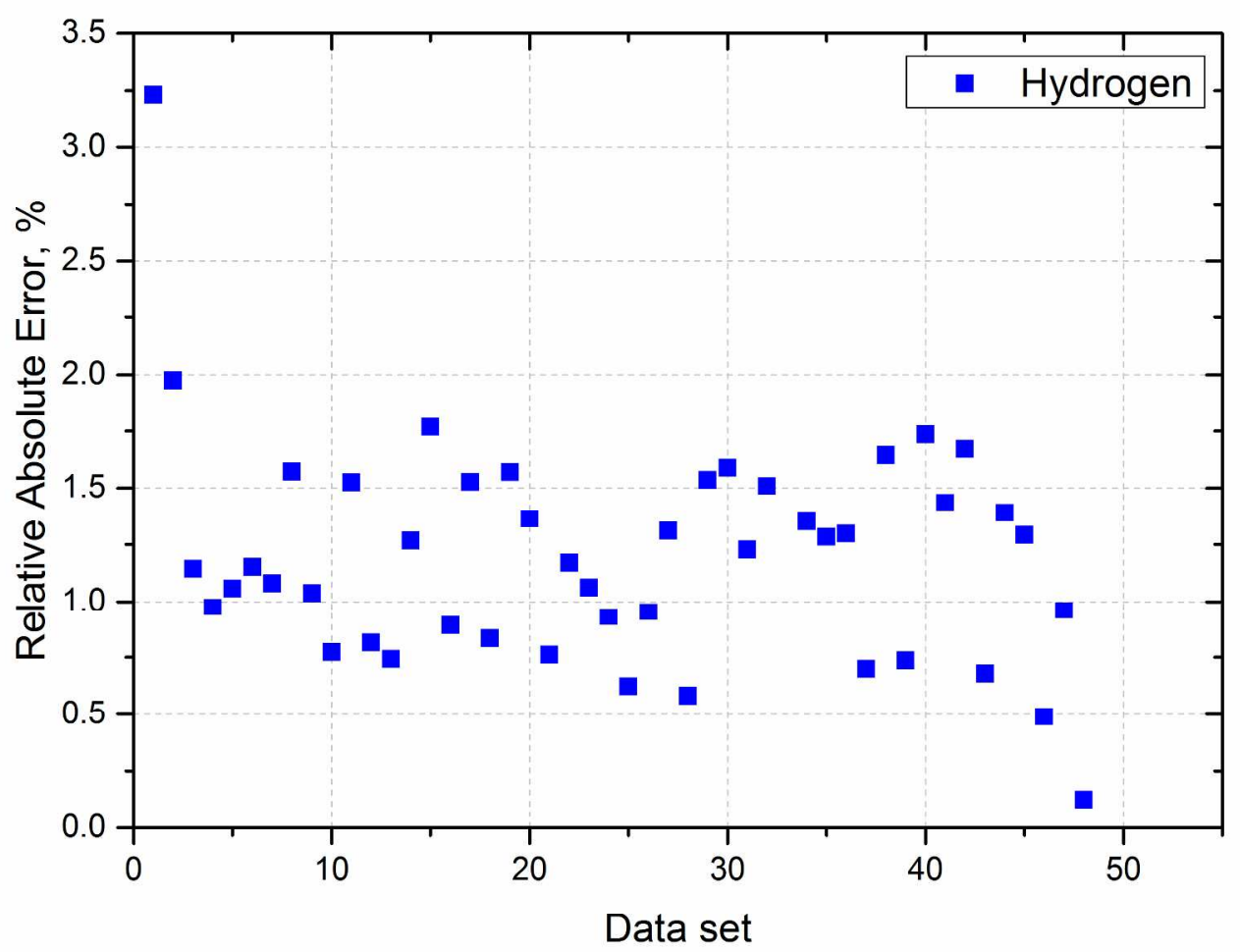

Figure 3. RAEs for the hydrogen predicted values from different experimental data sets 


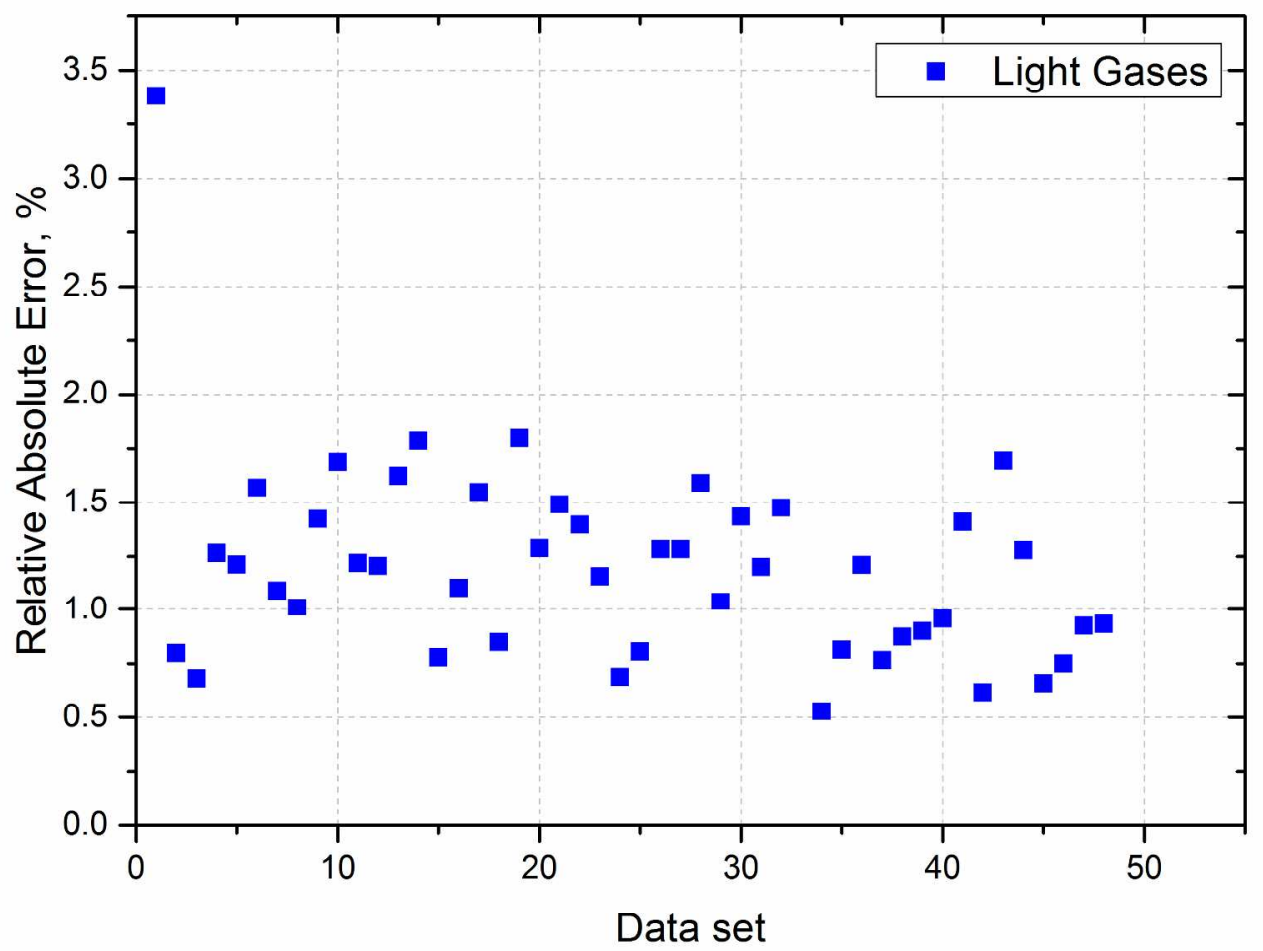

Figure 4. RAEs for the light gas predicted values from different experimental data sets 


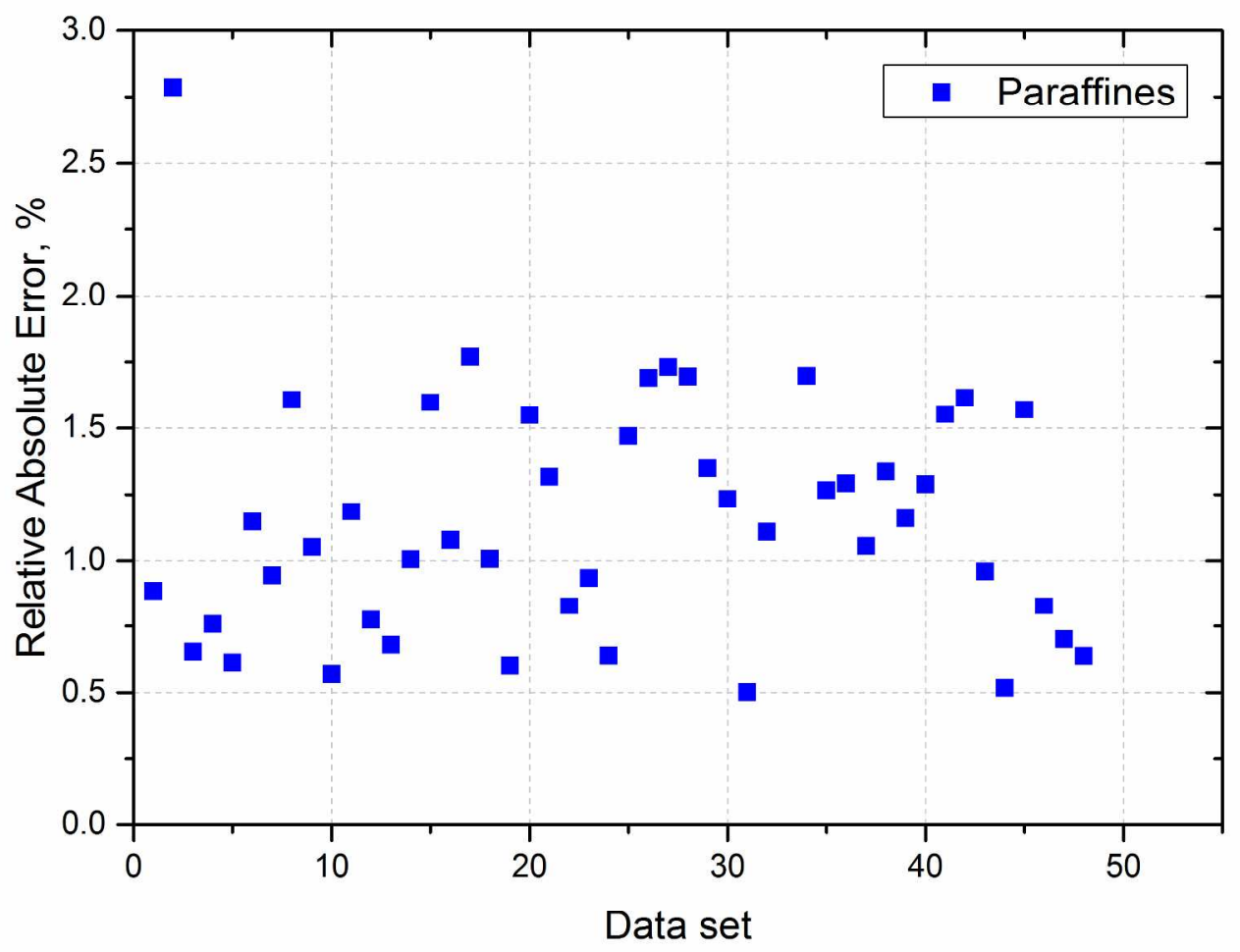

Figure 5. RAEs for the paraffin predicted values from different experimental data sets 


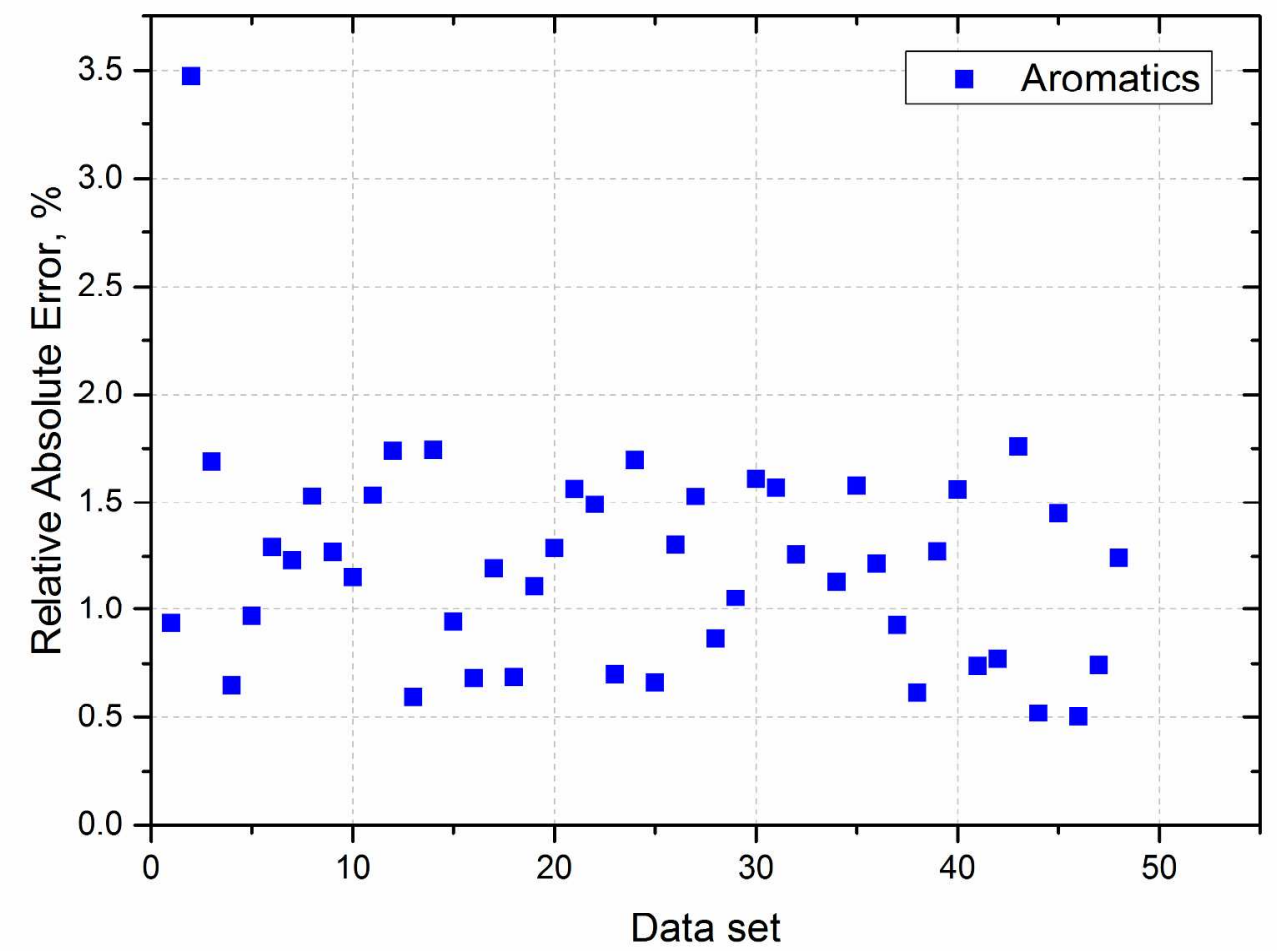

Figure 6. RAEs for the aromatics predicted values from different experimental data sets 


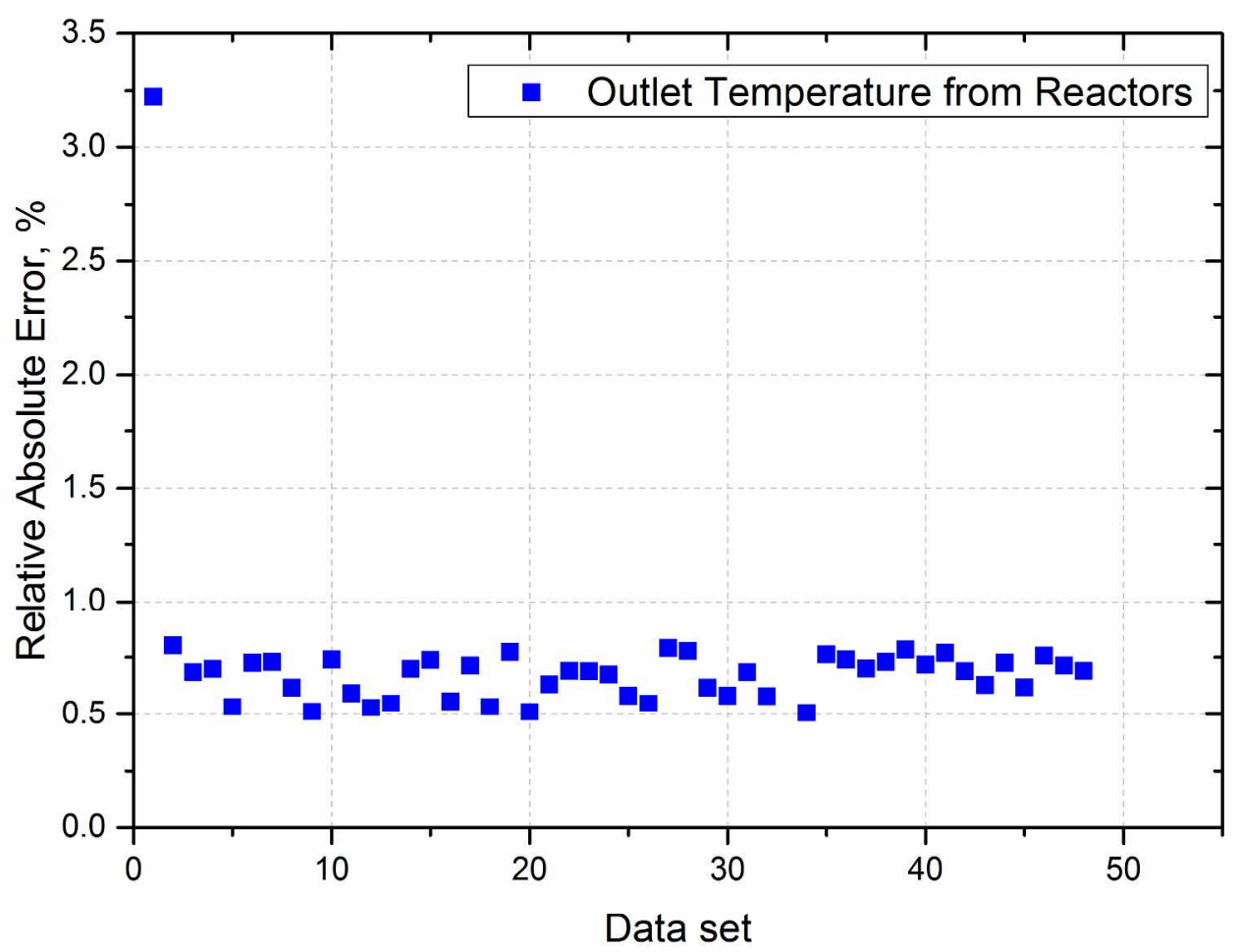

Figure 7. RAEs for the outlet reactor temperature predicted values from different experimental data sets 


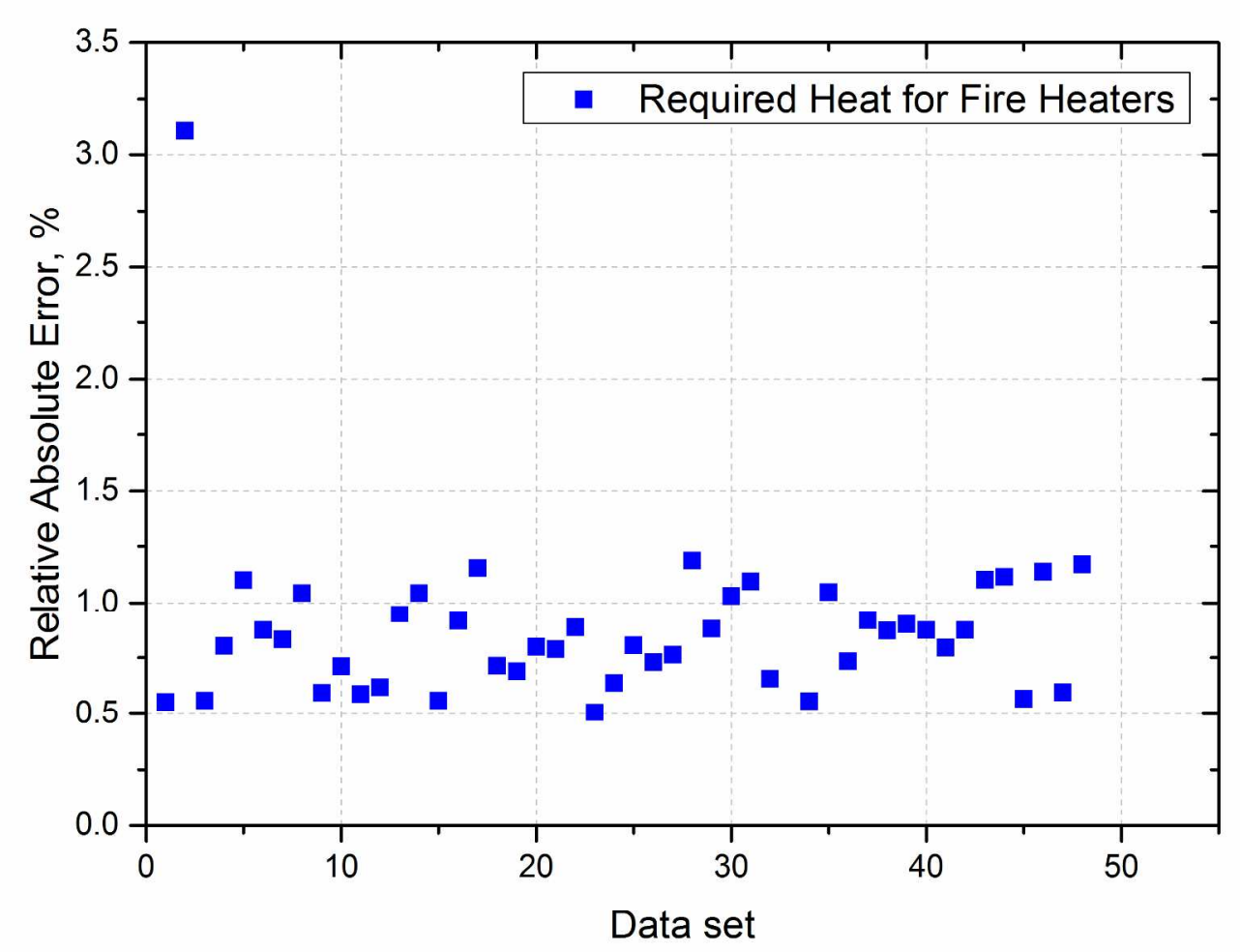

Figure 8. RAEs for the predicted fired heater duties from different experimental data sets 


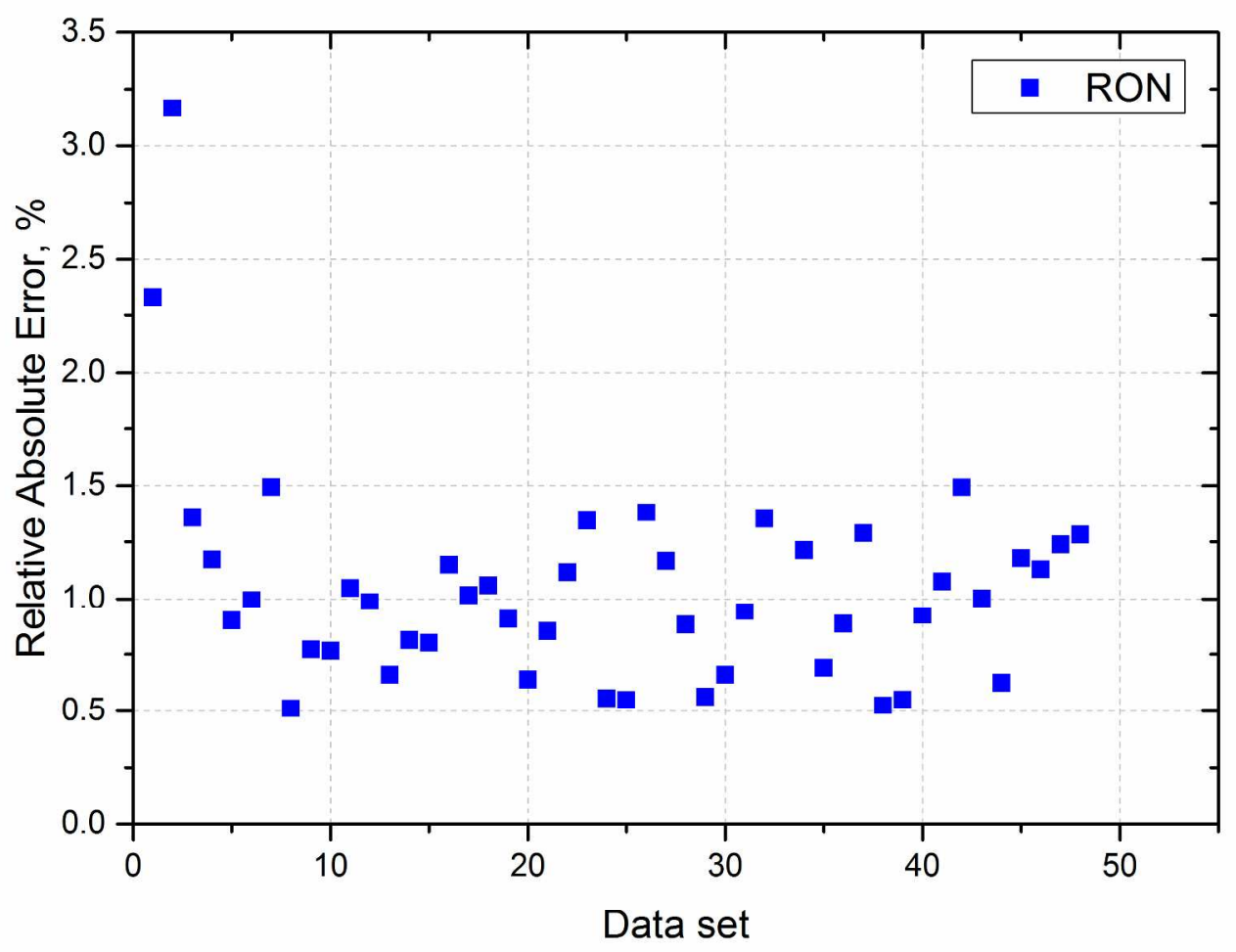

Figure 9. RAEs for RON predicted values from different experimental data sets 


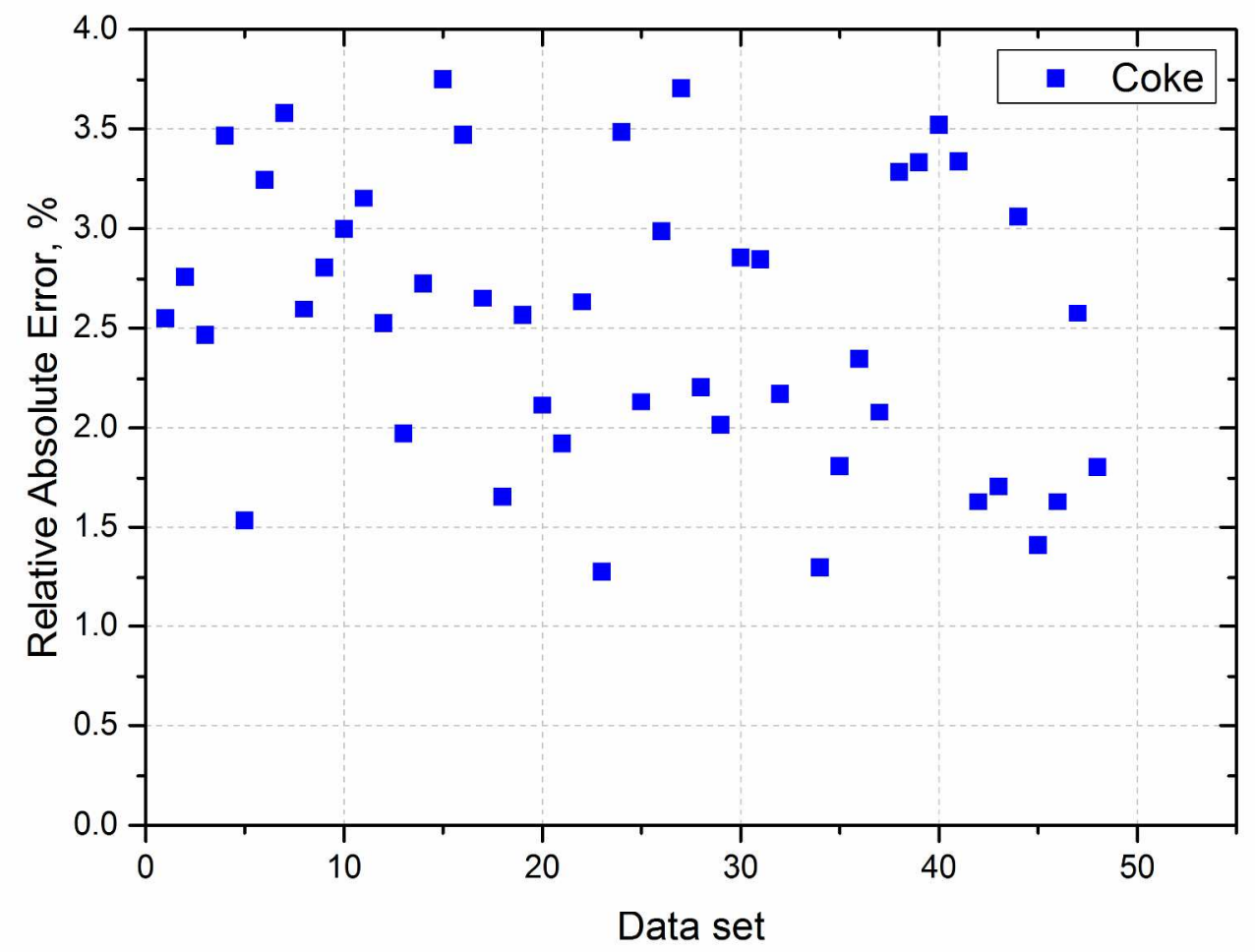

Figure 10. RAEs for coke predicted values from different experimental data sets 
Table 2. Range of operating conditions

\begin{tabular}{|c|c|c|c|}
\hline $\begin{array}{l}\text { Operating } \\
\text { parameter }\end{array}$ & Units & Lower & Upper \\
\hline Feed Charge & ton/day & 727 & 2949 \\
\hline $\mathrm{H}_{2} / \mathrm{HC}$ & - & 0.69 & 8.4 \\
\hline$W A I T^{*}$ & ${ }^{\circ} \mathrm{C}$ & 400 & 520 \\
\hline in $T_{1}$ & ${ }^{\circ} \mathrm{C}$ & 428 & 520 \\
\hline in $T_{2}$ & ${ }^{\circ} \mathrm{C}$ & 428 & 520 \\
\hline$i n T_{3}$ & ${ }^{\circ} \mathrm{C}$ & 433 & 520 \\
\hline in $T_{4}$ & ${ }^{\circ} \mathrm{C}$ & 430 & 520 \\
\hline$i n P_{1}$ & $\mathrm{kPa}$ & 370 & 517 \\
\hline
\end{tabular}

\begin{tabular}{l|l|l|l} 
Average catalyst & $\mathrm{kg} / \mathrm{day}$ & 560 & 683 \\
circulation rate & & & \\
\hline
\end{tabular}

* Weighted Average Inlet Temperature 
Table 2. Composition ranges of feedstock and reformate in $\mathrm{wt} \%$

\begin{tabular}{|c|c|c|c|c|c|}
\hline \multicolumn{3}{|l|}{ Feedstock } & \multicolumn{3}{|c|}{ Components in reformate } \\
\hline & Min & Max & & Min & Max \\
\hline $\mathbf{P 4}$ & 0 & 0 & P4 & 1.09 & 1.93 \\
\hline P5 & 0 & 0 & P5 & 2.17 & 2.86 \\
\hline P6 & 0.32 & 1.13 & P6 & 1.92 & 2.73 \\
\hline P7 & 9.02 & 12.75 & P7 & 6.3 & 8.3 \\
\hline P8 & 12.68 & 15.77 & P8 & 3.21 & 5.1 \\
\hline P9 & 12.42 & 17.37 & P9 & 0.84 & 1.92 \\
\hline P10+ & 7.99 & 10.14 & P10+ & 0.16 & 0.52 \\
\hline N5 & 0 & 0 & 06 & 0.09 & 0.1 \\
\hline N6 & 1.58 & 2.31 & 07 & 1.63 & 1.74 \\
\hline N7 & 9.64 & 10.55 & 08 & 0.03 & 0.04 \\
\hline N8 & 9.17 & 13.34 & 09 & 0 & 0 \\
\hline N9 & 10.7 & 12.28 & $010+$ & 0 & 0 \\
\hline N10 & 0.65 & 6.26 & N5 & 0.05 & 0.06 \\
\hline N11 & 0.83 & 1.0 & N6 & 0.18 & 0.32 \\
\hline Polynafthenes & 0.33 & 0.42 & $\mathbf{N} 7$ & 0.2 & 0.36 \\
\hline A6 & 0.11 & 0.1 & N8 & 0.14 & 0.62 \\
\hline A7 & 2.02 & 2.4 & N9 & 0.06 & 0.06 \\
\hline A8 & 2.95 & 4.47 & A6 & 1.93 & 2.66 \\
\hline A9 & 3.54 & 5.03 & A7 & 14.28 & 15.56 \\
\hline A10 & 0.58 & 2.63 & A8 & 22.56 & 25.34 \\
\hline
\end{tabular}




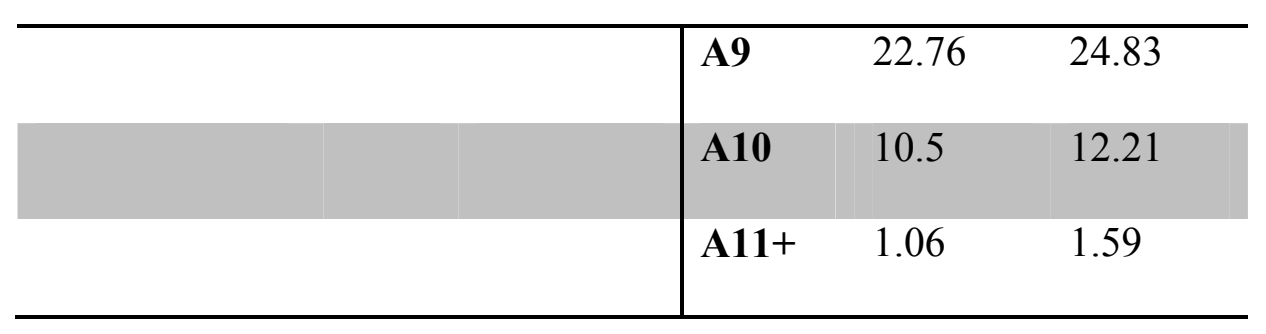

Table 3. Composition ranges of recycle gas, net hydrogen, LPG and fuel gas in mol \%

\begin{tabular}{lcccc|c|c|c|c}
\hline & \multicolumn{3}{c}{ Recycle gas } & \multicolumn{2}{c}{ Net hydrogen } & \multicolumn{2}{c}{ LPG } & \multicolumn{2}{c}{ Fuel gas } \\
\hline & Min & Max & Min & Max & Min & Max & Min & Max \\
\hline H2 & 88.4 & 92 & 92.5 & 93.76 & 0.05 & 0.18 & 25.4 & 36.7 \\
\hline C1 & 1.4 & 1.8 & 1.5 & 1.8 & 0.06 & 0.4 & 3.7 & 5.6 \\
\hline C2 & 1.7 & 1.9 & 1.97 & 2.1 & 3.96 & 10.6 & 24.8 & 31.2 \\
\hline C3 & 1.6 & 2 & 1.3 & 1.87 & 38.7 & 59.5 & 22.3 & 38.8 \\
\hline C4 & 1.3 & 1.91 & 0.62 & 0.9 & 31.5 & 53.7 & 6.1 & 10.3 \\
\hline C5 & 0.7 & 1.2 & 0.17 & 0.3 & 0.01 & 5.85 & 0.1 & 0.9 \\
\hline C6+ & 0.1 & 1.7 & 0.1 & 0.55 & 0.01 & 0.37 & 0.0 & 0.0 \\
\hline
\end{tabular}


Table 4. Composition ranges of coke before and after regeneration

\begin{tabular}{lccc}
\hline Coke content & Units & Min & Max \\
\hline Before regeneration & $w t \%$ & 4.06 & 6.80 \\
After regeneration & $w t \%$ & 0.05 & 0.1 \\
\hline
\end{tabular}


Table 5. List of pure components and pseudo-components

\begin{tabular}{|c|c|c|}
\hline $\begin{array}{c}\text { Pseudo-component } \\
\text { type }\end{array}$ & Symbol & Pseudo-components \\
\hline Normal paraffins & $\overline{n P_{i}}$ & $\begin{array}{l}\text { n-hexane } \\
\text { n-heptane } \\
\text { n-octane } \\
\text { n-nonane } \\
\text { n- decane } \\
\text { n- undekane }\end{array}$ \\
\hline Single branch paraffins & $S B P_{i}$ & $\begin{array}{l}\text { Single branch hexane } \\
\text { Single branch heptane } \\
\text { Single branch octane } \\
\text { Single branch nonane } \\
\text { Single branch decane } \\
\text { Single branch undekane }\end{array}$ \\
\hline Multi branch paraffins & $M B P_{i}$ & $\begin{array}{l}\text { Multi branch hexane } \\
\text { Multi branch heptane } \\
\text { Multi branch octane } \\
\text { Multi branch nonane } \\
\text { Multi branch decane } \\
\text { Multi branch undekane }\end{array}$ \\
\hline Alkylcyclopentanes & $5 N_{i}$ & $\begin{array}{l}\text { Cyclopentanes } \\
\text { Methylcyclopentane }\end{array}$ \\
\hline
\end{tabular}


Alkylcyclopentanes with 7 carbon atoms Alkylcyclopentanes with 8 carbon atoms Alkylcyclopentanes with 9 carbon atoms Alkylcyclopentanes with 10 carbon atoms Alkylcyclopentanes with 11 carbon atoms

\begin{tabular}{|c|c|c|}
\hline \multirow[t]{7}{*}{ Alkylcyclohexane } & $6 N_{i}$ & Cyclohexane \\
\hline & & Methylcyclohexane \\
\hline & & Alkylcyclohexane with 7 carbon atoms \\
\hline & & Alkylcyclohexane with 8 carbon atoms \\
\hline & & Alkylcyclohexane with 9 carbon atoms \\
\hline & & Alkylcyclohexane with 10 carbon atoms \\
\hline & & Alkylcyclohexane with 11 carbon atoms \\
\hline \multirow[t]{6}{*}{ Aromatics } & $A_{i}$ & Benzene \\
\hline & & Toluene \\
\hline & & Six ring aromatics with 8 carbon atoms \\
\hline & & Six ring aromatics with 9 carbon atoms \\
\hline & & Six ring aromatics with 10 carbon atoms \\
\hline & & Six ring aromatics with 11 carbon atoms \\
\hline \multirow[t]{6}{*}{ Olefins } & $O l_{i}$ & Olefins with 6 carbon atoms \\
\hline & & Olefins with 7 carbon atoms \\
\hline & & Olefins with 8 carbon atoms \\
\hline & & Olefins with 9 carbon atoms \\
\hline & & Olefins with 10 carbon atoms \\
\hline & & Olefins with 11 carbon atoms \\
\hline \multirow[t]{3}{*}{ Light gases } & $\boldsymbol{P}_{\boldsymbol{i}}$ & Methane \\
\hline & & Ethane \\
\hline & & Propane \\
\hline
\end{tabular}


Parffins with 4 carbon atoms

Parffins with 5 carbon atoms

\begin{tabular}{lll} 
Hydrogen & $\boldsymbol{H}_{2}$ & Hydrogen \\
Coke & $\boldsymbol{C}_{\text {oke }}$ & Coke \\
\hline
\end{tabular}


Table 6. Proposed kinetics model and kinetic parameters

\begin{tabular}{|c|c|c|c|}
\hline Isomerization of normal paraffins & $\xi_{r x}=1$ & Aref $_{r x}$ & $\operatorname{Eref}_{r x}(\mathrm{~kJ} / \mathrm{mol})$ \\
\hline \multicolumn{2}{|l|}{$n P_{6} \leftrightarrow S B P_{6}$} & $19.5553 \pm 0.1154$ & $180.7522 \pm$ \\
\hline \multicolumn{2}{|l|}{$n P_{7} \leftrightarrow S B P_{7}$} & $20.9384 \pm 0.0945$ & 2.4785 \\
\hline \multicolumn{2}{|l|}{$n P_{8} \leftrightarrow S B P_{8}$} & $21.0933 \pm 0.5805$ & \\
\hline \multicolumn{2}{|l|}{$n P_{9} \leftrightarrow S B P_{9}$} & $22.7233 \pm 0.6771$ & \\
\hline \multicolumn{2}{|l|}{$n P_{10} \leftrightarrow S B P_{10}$} & $23.2579 \pm 0.1891$ & \\
\hline \multicolumn{2}{|l|}{$n P_{11} \leftrightarrow S B P_{11}$} & $24.6579 \pm 0.7286$ & \\
\hline Isomerization of single branch paraffins & $\xi_{r x}=1$ & & \\
\hline \multicolumn{2}{|l|}{$S B_{6} \leftrightarrow M B_{6}$} & $19.5553 \pm 0.6092$ & $180.7522 \pm$ \\
\hline \multicolumn{2}{|l|}{$S B_{7} \leftrightarrow M B_{7}$} & $20.9384 \pm 0.1978$ & 1.4785 \\
\hline \multicolumn{2}{|l|}{$S B_{8} \leftrightarrow M B_{8}$} & $20.9933 \pm 0.4062$ & \\
\hline \multicolumn{2}{|l|}{$S B_{9} \leftrightarrow M B_{9}$} & $20.7237 \pm 0.2060$ & \\
\hline \multicolumn{2}{|l|}{$S B_{10} \leftrightarrow M B_{10}$} & $21.8579 \pm 0.1692$ & \\
\hline \multicolumn{2}{|l|}{$S B_{11} \leftrightarrow M B_{11}$} & $23.1569 \pm 1.0475$ & \\
\hline Ring closure of $n$-paraffins & $\xi_{r x}=1$ & & \\
\hline \multicolumn{2}{|l|}{$P_{5} \leftrightarrow 5 N_{5}+H_{2}$} & $37.3375 \pm 0.8432$ & $222.7791 \pm$ \\
\hline \multicolumn{2}{|l|}{$n P_{6} \leftrightarrow 5 N_{6}+H_{2}$} & $38.1582 \pm 1.3603$ & 2.0455 \\
\hline \multicolumn{2}{|l|}{$n P_{7} \leftrightarrow 5 N_{7}+H_{2}$} & $38.7486 \pm 1.3363$ & \\
\hline \multicolumn{2}{|l|}{$n P_{8} \leftrightarrow 5 N_{8}+H_{2}$} & $38.9900 \pm 0.6379$ & \\
\hline \multicolumn{2}{|l|}{$n P_{9} \leftrightarrow 5 N_{9}+H_{2}$} & $39.2584 \pm 0.6129$ & \\
\hline \multicolumn{2}{|l|}{$n P_{10} \leftrightarrow 5 N_{10}+H_{2}$} & $39.8964 \pm 0.4520$ & \\
\hline \multicolumn{2}{|l|}{$n P_{11} \leftrightarrow 5 N_{11}+H_{2}$} & $40.5878 \pm 0.423$ & \\
\hline Ring expansion of cyclopentanes & $\xi_{r x}=1$ & & \\
\hline \multicolumn{2}{|l|}{$5 N_{6} \leftrightarrow 6 N_{6}$} & $20.8425 \pm 0.9729$ & $184.5445 \pm$ \\
\hline \multicolumn{2}{|l|}{$5 N_{7} \leftrightarrow 6 N_{7}$} & $22.4352 \pm 0.4586$ & 1.8062 \\
\hline \multicolumn{2}{|l|}{$5 N_{8} \leftrightarrow 6 N_{8}$} & $22.0994 \pm 0.2458$ & \\
\hline \multicolumn{2}{|l|}{$5 N_{9} \leftrightarrow 6 N_{9}$} & $23.7602 \pm 0.7916$ & \\
\hline \multicolumn{2}{|l|}{$5 N_{10} \leftrightarrow 6 N_{10}$} & $24.5759 \pm 1.0643$ & \\
\hline \multicolumn{2}{|l|}{$5 N_{11} \leftrightarrow 6 N_{11}$} & $25.7757 \pm 0.3991$ & \\
\hline Dehydrogenation of cyclohexanes & $\xi_{r x}=1$ & & \\
\hline
\end{tabular}




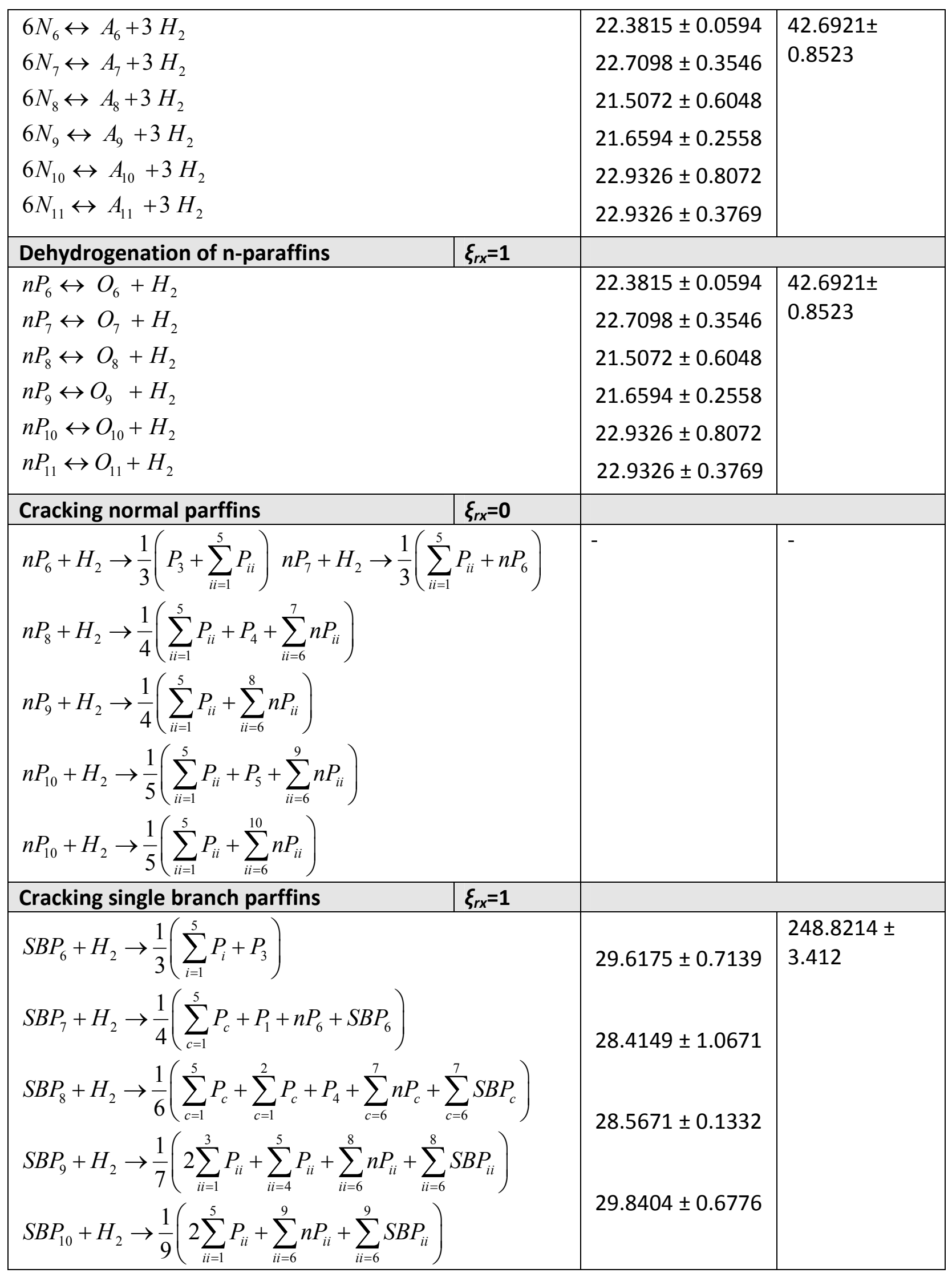




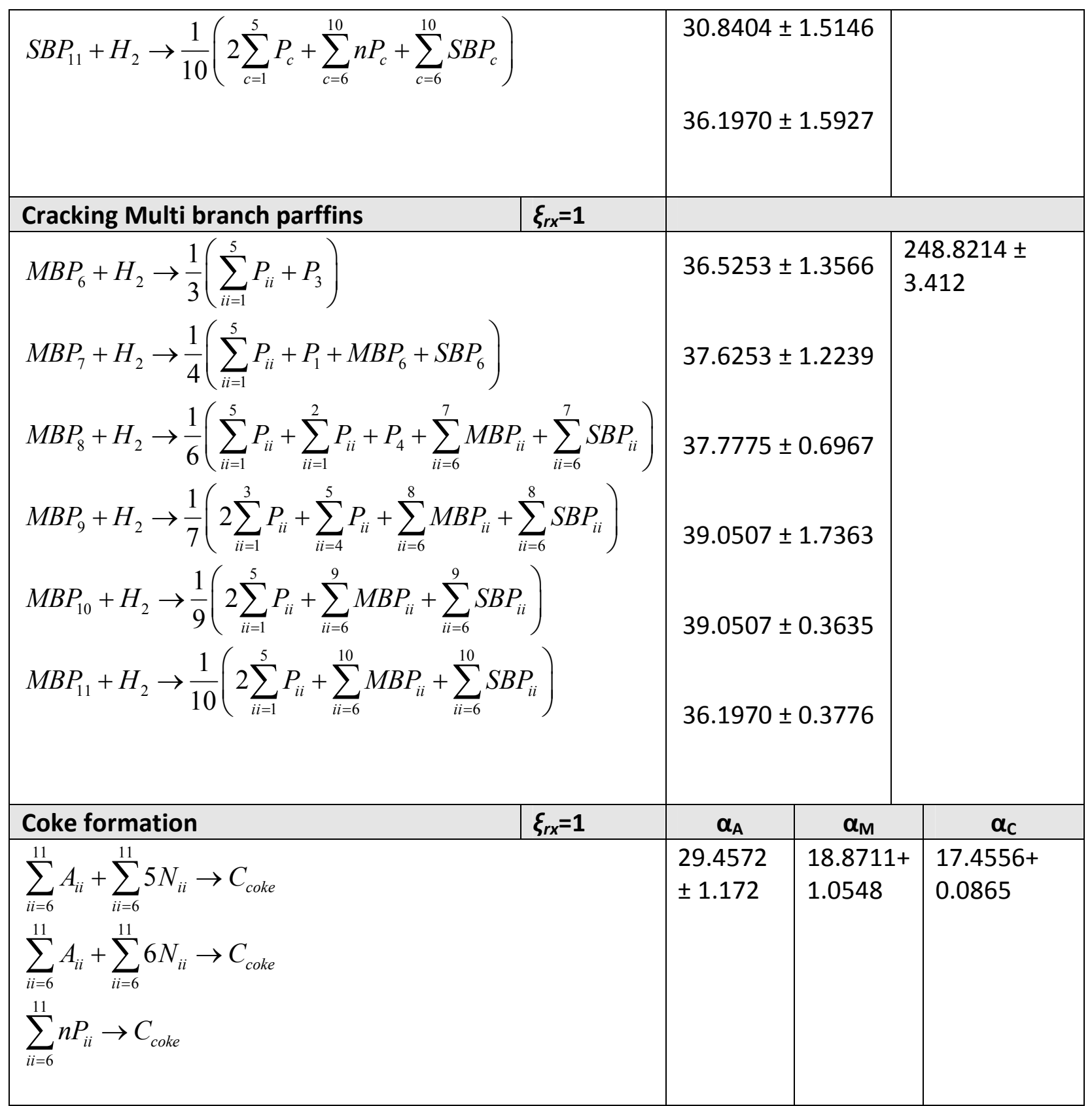

Table 7. Component compositions predicted by the model (measured at the inlet and outlet of each reaction section)

\begin{tabular}{|l|c|c|c|c|}
\hline $\begin{array}{l}\text { Component } \\
\mathrm{s}\end{array}$ & $\begin{array}{c}\text { Unit } \\
\mathrm{s}\end{array}$ & Test Run 3 & Test Run 2 & Test Run 3 \\
\hline
\end{tabular}




\begin{tabular}{|c|c|c|c|c|c|c|c|c|c|c|}
\hline & & Inlet & $\begin{array}{l}\text { Measure } \\
\text { d }\end{array}$ & Calculated & Inlet & $\begin{array}{l}\text { Measure } \\
\text { d }\end{array}$ & $\begin{array}{l}\text { Calculat } \\
\text { ed }\end{array}$ & Inlet & $\begin{array}{l}\text { Measure } \\
1\end{array}$ & Calculated \\
\hline H2 & $\begin{array}{r}\text { wt. } \\
\%\end{array}$ & 4.341 & 7.303 & 7.267 & 5.580 & 8.635 & 8.552 & 5.271 & 7.784 & 7.794 \\
\hline C1 & $\begin{array}{r}\text { wt. } \\
\%\end{array}$ & 0.547 & 1.025 & 1.031 & 0.703 & 1.203 & 1.194 & 0.664 & 1.030 & 1.021 \\
\hline C2 & $\begin{array}{r}\text { wt. } \\
\%\end{array}$ & 1.245 & 2.102 & 2.117 & 1.601 & 2.576 & 2.553 & 1.512 & 1.954 & 1.942 \\
\hline C3 & $\begin{array}{r}\text { wt. } \\
\% \\
\end{array}$ & 1.719 & 2.338 & 2.346 & 2.209 & 3.404 & 3.381 & 2.087 & 3.046 & 3.040 \\
\hline P4 & $\begin{array}{r}\text { wt. } \\
\%\end{array}$ & 0.020 & 3.859 & 3.854 & 0.025 & 4.161 & 4.170 & 0.024 & 3.151 & 3.177 \\
\hline P5 & $\begin{array}{r}\text { wt. } \\
\%\end{array}$ & 0.012 & 3.052 & 3.032 & 0.016 & 3.271 & 3.256 & 0.015 & 2.966 & 2.989 \\
\hline P6 & $\begin{array}{r}\text { wt. } \\
\%\end{array}$ & 0.430 & 2.265 & 2.270 & 0.422 & 6.146 & 6.112 & 2.535 & 6.466 & 6.474 \\
\hline P7 & $\begin{array}{r}\text { wt. } \\
\%\end{array}$ & 8.329 & 5.385 & 5.430 & 8.126 & 0.640 & 0.636 & $\begin{array}{c}11.35 \\
3\end{array}$ & 0.694 & 0.690 \\
\hline P8 & $\begin{array}{r}\text { wt. } \\
\% \\
\end{array}$ & $\begin{array}{c}11.68 \\
3\end{array}$ & 2.821 & 2.805 & $\begin{array}{c}11.39 \\
7\end{array}$ & 0.024 & 0.024 & $\begin{array}{c}10.12 \\
0\end{array}$ & 0.026 & 0.026 \\
\hline P9 & $\begin{array}{r}\text { wt. } \\
\%\end{array}$ & $\begin{array}{c}11.44 \\
3\end{array}$ & 0.803 & 0.807 & $\begin{array}{c}11.16 \\
4\end{array}$ & 0.000 & 0.000 & 8.411 & 0.000 & 0.000 \\
\hline P10 & $\begin{array}{r}\text { wt. } \\
\%\end{array}$ & 9.112 & 0.162 & 0.162 & 8.890 & 1.936 & 1.946 & 9.452 & 2.100 & 2.090 \\
\hline P11 & $\begin{array}{r}\text { wt. } \\
\%\end{array}$ & 0.000 & 0.000 & 0.000 & 0.000 & 0.000 & 0.000 & 0.000 & 0.000 & 0.000 \\
\hline N5 & $\begin{array}{r}\text { wt. } \\
\%\end{array}$ & 0.000 & 0.051 & 0.052 & 1.438 & 0.063 & 0.063 & 0.010 & 0.069 & 0.068 \\
\hline N6 & $\begin{array}{l}\text { wt. } \\
\%\end{array}$ & 1.474 & 0.182 & 0.169 & 9.024 & 0.196 & 0.189 & 2.517 & 0.239 & 0.204 \\
\hline N7 & $\begin{array}{r}\text { wt. } \\
\%\end{array}$ & 9.250 & 0.145 & 0.170 & $\begin{array}{c}11.99 \\
1\end{array}$ & 0.046 & 0.087 & $\begin{array}{c}11.72 \\
7\end{array}$ & 0.045 & 0.093 \\
\hline N8 & $\begin{array}{l}\text { wt. } \\
\%\end{array}$ & $\begin{array}{c}12.29 \\
1\end{array}$ & 0.130 & 0.120 & $\begin{array}{c}11.02 \\
9\end{array}$ & 0.000 & 0.000 & $\begin{array}{c}14.03 \\
2\end{array}$ & 0.000 & 0.000 \\
\hline N9 & $\begin{array}{r}\text { wt. } \\
\%\end{array}$ & $\begin{array}{c}11.30 \\
5\end{array}$ & 0.000 & 0.000 & 5.465 & 0.056 & 0.047 & $\begin{array}{c}12.14 \\
1\end{array}$ & 0.061 & 0.051 \\
\hline N10 & $\begin{array}{r}\text { wt. } \\
\%\end{array}$ & 5.602 & 0.000 & 0.000 & 0.908 & 0.000 & 0.000 & 0.000 & 0.000 & 0.000 \\
\hline N11 & $\begin{array}{l}\text { wt. } \\
\%\end{array}$ & 0.931 & 0.000 & 0.000 & 0.126 & 0.000 & 0.000 & 0.000 & 0.000 & 0.000 \\
\hline A6 & $\begin{array}{r}\text { wt. } \\
\%\end{array}$ & 0.129 & 1.778 & 1.769 & 2.139 & 1.736 & 1.723 & 0.324 & 12.589 & 12.495 \\
\hline A7 & $\begin{array}{l}\text { wt. } \\
\%\end{array}$ & 2.193 & 13.129 & 13.195 & 3.991 & 12.821 & 12.885 & 2.204 & 24.552 & 24.770 \\
\hline A8 & wt. & 4.091 & 21.660 & 21.706 & 3.236 & 21.151 & 21.286 & 2.396 & 21.047 & 20.785 \\
\hline
\end{tabular}




\begin{tabular}{|c|c|c|c|c|c|c|c|c|c|c|}
\hline & $\%$ & & & & & & & & & \\
\hline A9 & $\begin{array}{c}\text { wt. } \\
\%\end{array}$ & 3.317 & 21.036 & 20.943 & 0.521 & 20.541 & 20.475 & 1.941 & 11.081 & 11.185 \\
\hline A10 & $\begin{array}{c}\text { wt. } \\
\%\end{array}$ & 0.534 & 10.061 & 10.036 & 0.000 & 9.824 & 9.868 & 1.264 & 0.617 & 0.624 \\
\hline A11 & $\begin{array}{c}\text { wt. } \\
\%\end{array}$ & 0.000 & 0.000 & 0.000 & 0.000 & 0.000 & 0.000 & 0.000 & 0.000 & 0.000 \\
\hline O6 & $\begin{array}{c}\text { wt. } \\
\%\end{array}$ & 0.000 & 0.150 & 0.155 & 0.000 & 0.249 & 0.247 & 0.000 & 0.195 & 0.194 \\
\hline $\mathrm{O} 7$ & $\begin{array}{r}\text { wt. } \\
\%\end{array}$ & 0.000 & 0.290 & 0.296 & 0.000 & 0.246 & 0.240 & 0.000 & 0.134 & 0.137 \\
\hline 08 & $\begin{array}{r}\text { wt. } \\
\%\end{array}$ & 0.000 & 0.149 & 0.146 & 0.000 & 0.767 & 0.750 & 0.000 & 0.108 & 0.099 \\
\hline O9 & $\begin{array}{c}\text { wt. } \\
\%\end{array}$ & 0.000 & 0.125 & 0.120 & 0.000 & 0.308 & 0.316 & 0.000 & 0.049 & 0.052 \\
\hline 010 & $\begin{array}{c}\text { wt. } \\
\%\end{array}$ & 0.000 & 0.000 & 0.000 & 0.000 & 0.000 & 0.000 & 0.000 & 0.000 & 0.000 \\
\hline 011 & $\begin{array}{c}\text { wt. } \\
\%\end{array}$ & 0.000 & 0.000 & 0.000 & 0.000 & 0.000 & 0.000 & 0.000 & 0.000 & 0.000 \\
\hline Coke & $\begin{array}{c}\text { wt. } \\
\%\end{array}$ & 0.060 & 6.010 & 5.912 & 0.080 & 4.850 & 4.975 & 0.110 & 5.540 & 5.440 \\
\hline RON & & & 102.5 & 103.6581 & & 100.2 & $\begin{array}{c}101.441 \\
7\end{array}$ & & 99.9 & 98.61855 \\
\hline
\end{tabular}

Table 8. A comparison between the predicted and measured outlet temperatures from each reactor, at the given inlet reactor conditions ${ }^{\circ} \mathrm{C}$

\begin{tabular}{|c|c|c|}
\hline Test Run 3 & Test Run 2 & Test Run 3 \\
\hline
\end{tabular}




\begin{tabular}{|c|c|c|c|c|c|c|c|c|c|}
\hline & Inlet & $\begin{array}{l}\text { Outlet } \\
\text { Measur } \\
\text { ed }\end{array}$ & $\begin{array}{l}\text { Outlet } \\
\text { Calculate } \\
\text { d }\end{array}$ & Inlet & $\begin{array}{l}\text { Measure } \\
\text { d }\end{array}$ & $\begin{array}{l}\text { Outlet } \\
\text { Calcul } \\
\text { ated }\end{array}$ & Inlet & $\begin{array}{l}\text { Outlet } \\
\text { Measur } \\
\text { ed }\end{array}$ & $\begin{array}{l}\text { Outlet } \\
\text { Calculat } \\
\text { ed }\end{array}$ \\
\hline Rx\#1 & $\begin{array}{r}517 . \\
850\end{array}$ & 391.3 & 388.347 & $\begin{array}{r}502.50 \\
0\end{array}$ & 378.7 & $\begin{array}{r}381.40 \\
2\end{array}$ & 500.0 & $\begin{array}{r}377.80 \\
0 \\
\end{array}$ & 375.911 \\
\hline Rx\#2 & $\begin{array}{c}517 . \\
865\end{array}$ & 443.9 & 446.872 & $\begin{array}{r}501.10 \\
0 \\
\end{array}$ & 432.5 & $\begin{array}{r}434.57 \\
0\end{array}$ & 500.1 & $\begin{array}{r}429.50 \\
0\end{array}$ & 426.579 \\
\hline Rx\#3 & $\begin{array}{r}517 . \\
876\end{array}$ & 468.3 & 465.031 & $\begin{array}{r}502.00 \\
0\end{array}$ & 457.5 & $\begin{array}{r}460.10 \\
7 \\
\end{array}$ & 500.0 & $\begin{array}{r}454.10 \\
0\end{array}$ & 451.512 \\
\hline Rx\#4 & $\begin{array}{r}517 . \\
876 \\
\end{array}$ & 479.6 & 482.414 & $\begin{array}{r}501.00 \\
0 \\
\end{array}$ & 469.2 & $\begin{array}{r}470.75 \\
8 \\
\end{array}$ & 500.0 & $\begin{array}{r}465.20 \\
0 \\
\end{array}$ & 461.987 \\
\hline
\end{tabular}

Table 9. Predicted and measured heat duties at the inlet and outlet of each fired heater

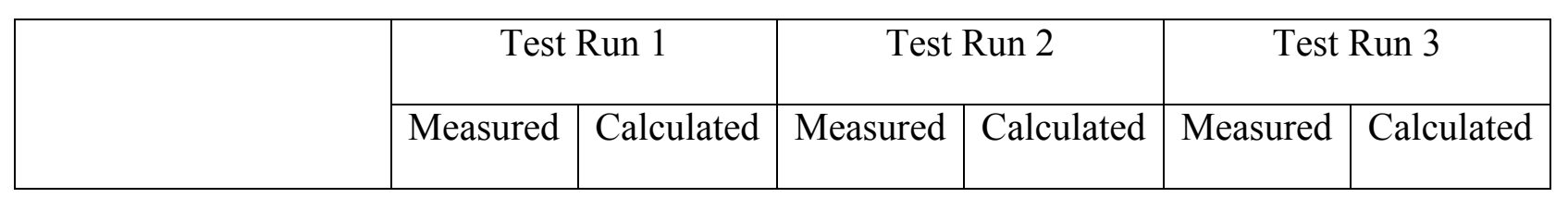




\begin{tabular}{|l|r|r|r|r|r|r|}
\hline Fired Heater\#1 & 8482.6 & 8579.182 & 6897 & 6931.485 & 7706.1 & 7796.351 \\
\hline Fired Heater\#2 & 16261.1 & 16101.74 & 15990.9 & 16086.13 & 17456.2 & 17630.76 \\
\hline Fired Heater\#3 & 8974.8 & 9067.24 & 8600.74 & 8562.037 & 9342.7 & 9244.602 \\
\hline Fired Heater\#4 & 5261 & 5214.177 & 4475.17 & 4459.507 & 4913.65 & 4866.479 \\
\hline
\end{tabular}




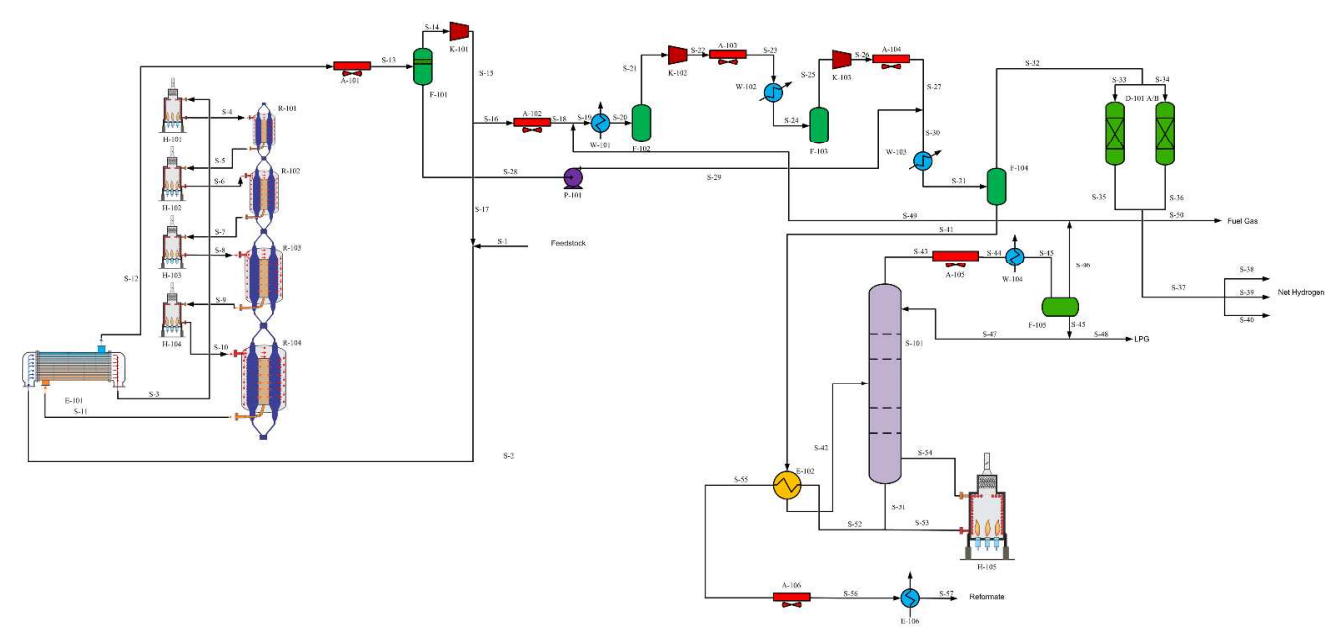

Figure 1. CCR Process Flowsheet

$427 \times 198 \mathrm{~mm}(300 \times 300$ DPI) 


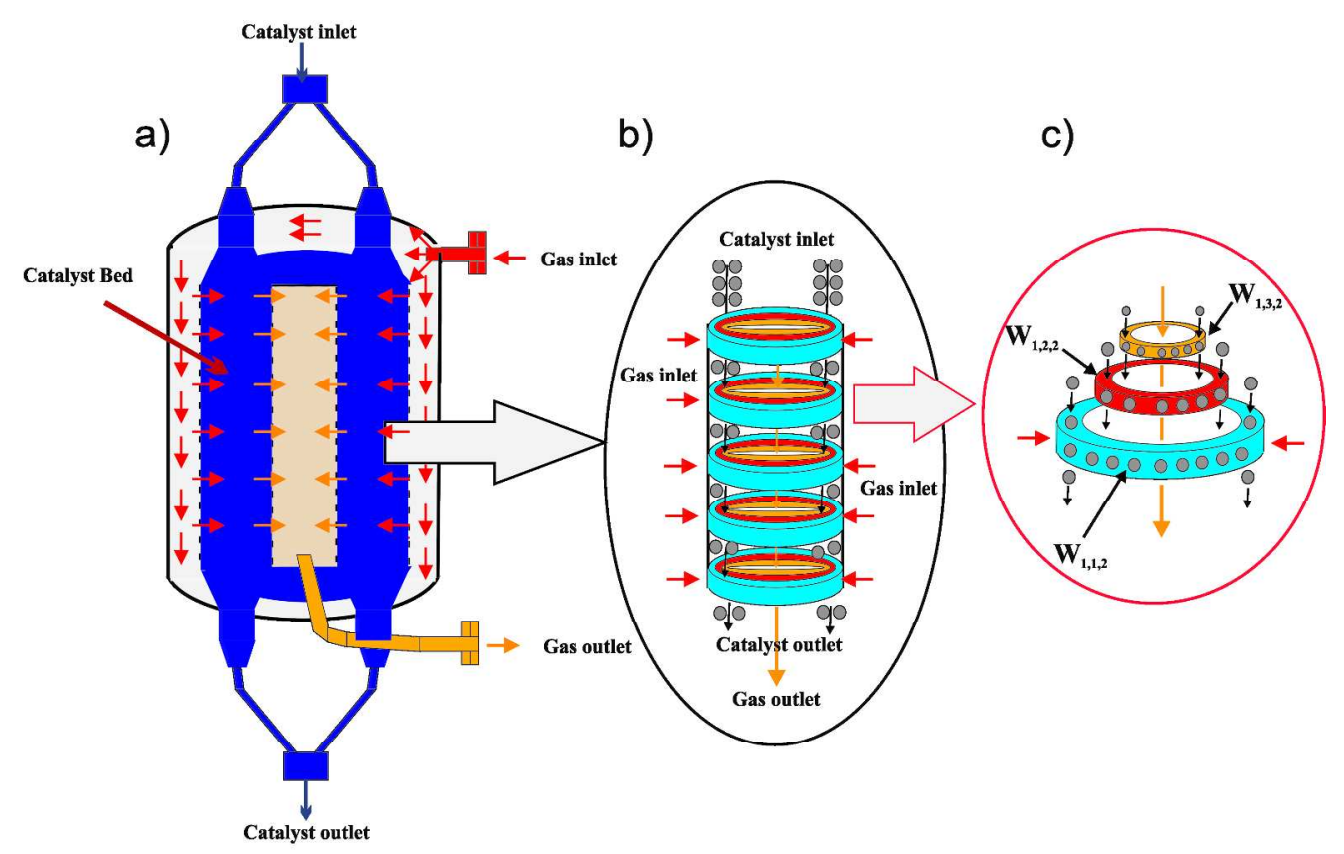

Figure 2. a) Moving bed radial flow reactor, b) Layers of moving bed, c) Reaction zones $273 \times 177 \mathrm{~mm}(300 \times 300 \mathrm{DPI})$ 


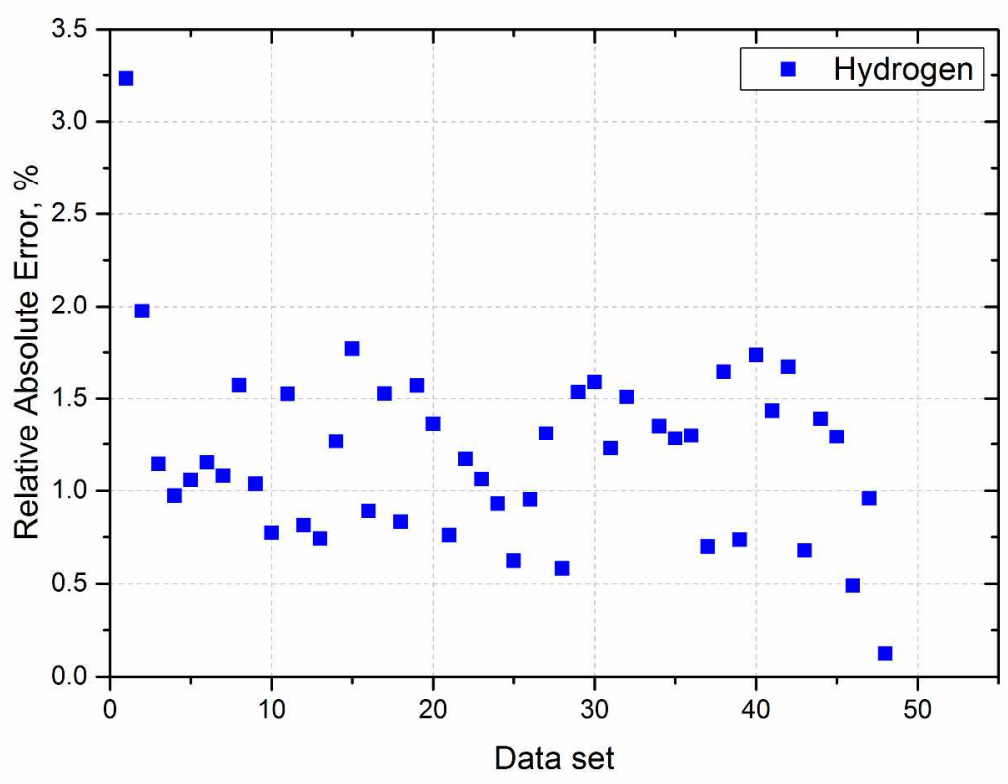

Figure 3. RAEs for the hydrogen predicted values from different experimental data sets $288 \times 200 \mathrm{~mm}(300 \times 300$ DPI $)$ 
Figure 4. RAEs for the light gas predicted values from different experimental data sets $288 \times 200 \mathrm{~mm}(300 \times 300$ DPI $)$ 


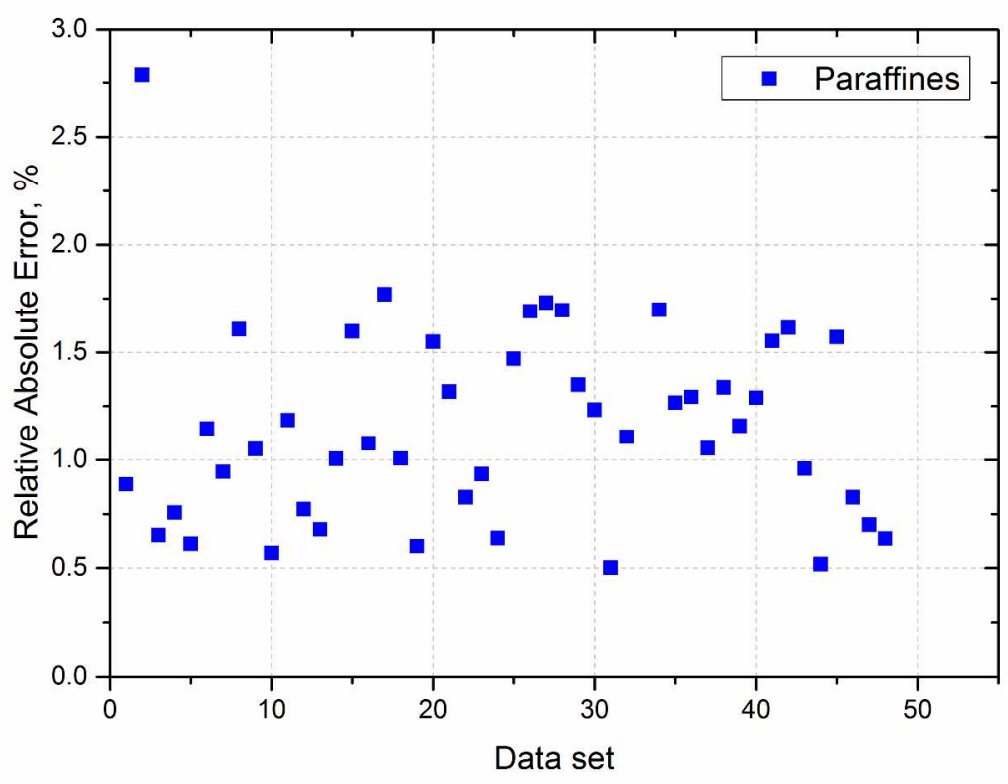

Figure 5. RAEs for the paraffin predicted values from different experimental data sets $288 \times 200 \mathrm{~mm}(300 \times 300$ DPI $)$ 
Figure 6. RAEs for the aromatics predicted values from different experimental data sets $288 \times 200 \mathrm{~mm}(300 \times 300$ DPI $)$ 


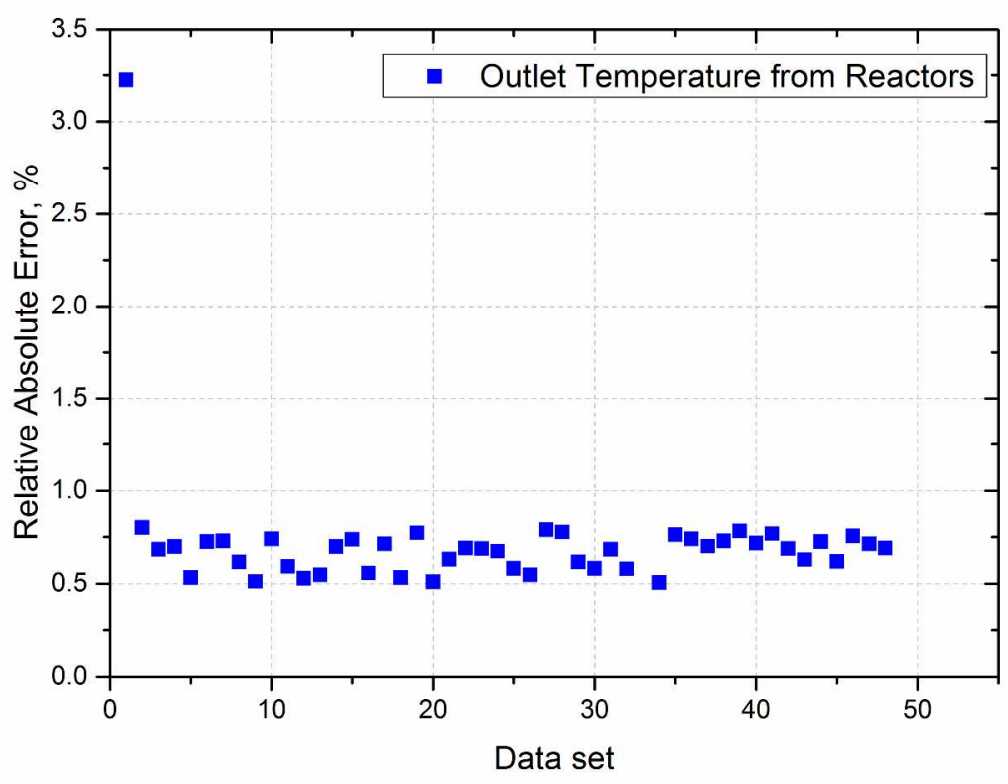

Figure 7. RAEs for the outlet reactor temperature predicted values from different experimental data sets $288 \times 200 \mathrm{~mm}(300 \times 300$ DPI $)$ 
Figure 8. RAEs for the predicted fired heater duties from different experimental data sets $288 \times 200 \mathrm{~mm}(300 \times 300$ DPI $)$ 


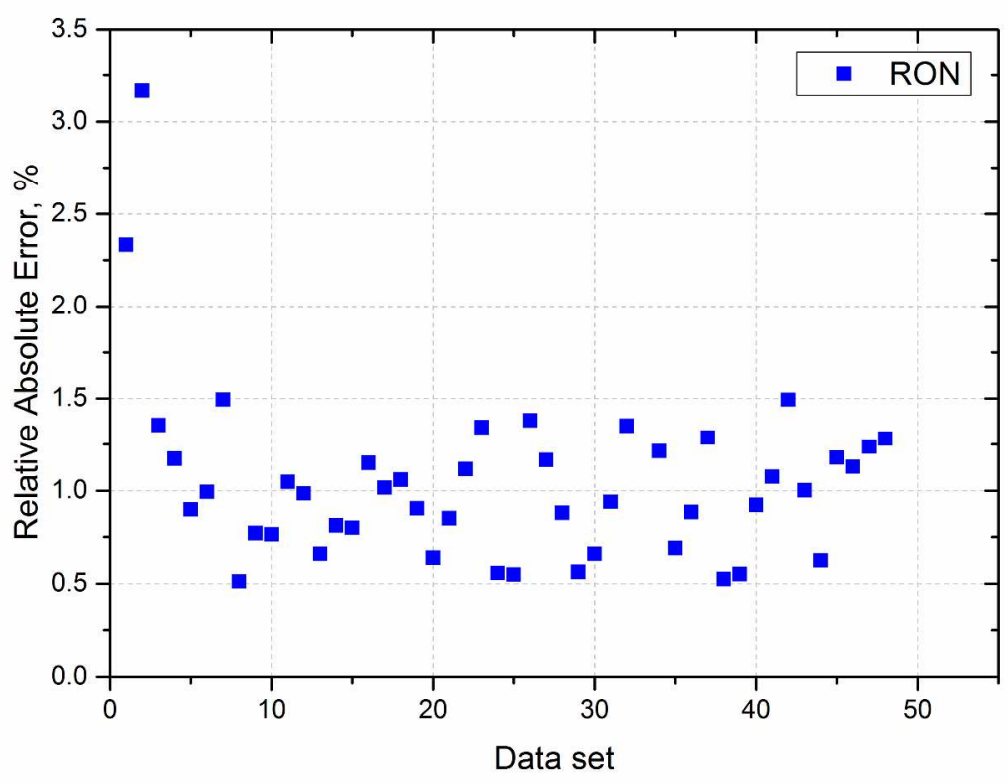

Figure 9. RAEs for RON predicted values from different experimental data sets $288 \times 200 \mathrm{~mm}(300 \times 300$ DPI $)$ 


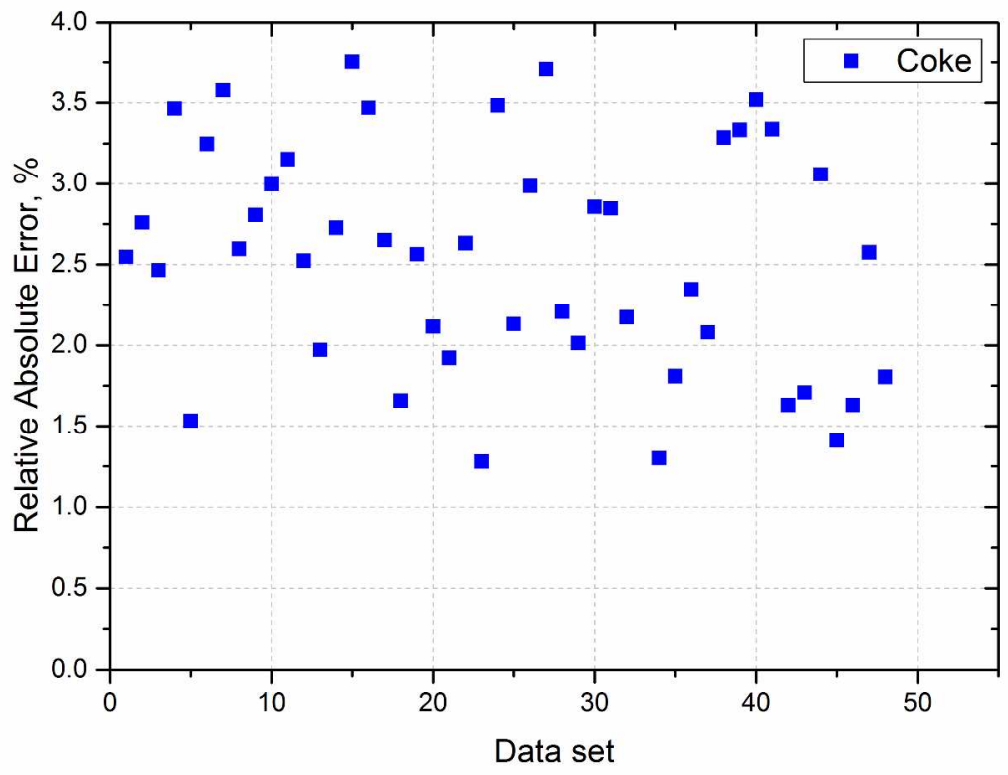

Figure 10. RAEs for coke predicted values from different experimental data sets $288 \times 200 \mathrm{~mm}(300 \times 300$ DPI $)$ 